\title{
Role of the tumor microenvironment in tumor progression and the clinical applications (Review)
}

\author{
YAO YUAN ${ }^{*}$, YU-CHEN JIANG ${ }^{*}$, CHONG-KUI SUN and QIAN-MING CHEN \\ State Key Laboratory of Oral Diseases, West China Hospital of Stomatology, \\ Sichuan University, Chengdu, Sichuan 610041, P.R. China
}

Received December 5, 2015; Accepted January 27, 2016

DOI: $10.3892 /$ or.2016.4660

\begin{abstract}
Oncogene activation and tumor-suppressor gene inactivation are considered as the main causes driving the transformation of normal somatic cells into malignant tumor cells. Cancer cells are the driving force of tumor development and progression. Yet, cancer cells are unable to accomplish this alone. The tumor microenvironment is also considered to play an active role rather than simply acting as a by-stander in tumor progression. Through different pathways, tumor cells efficiently recruit stromal cells, which in turn, provide tumor cell growth signals, intermediate metabolites, and provide a suitable environment for tumor progression as well as metastasis. Through reciprocal communication, cancer cells and the microenvironment act in collusion leading to high proliferation and metastatic capability. Understanding the role of the tumor microenvironment in tumor progression provides us with novel approaches through which to target the tumor microenvironment for efficient anticancer treatment. In this review, we summarize the mechanisms involved in the recruitment of stromal cells by tumor cells to the primary tumor site and highlight the role of the tumor microenvironment in the regulation of tumor progression. We further discuss the potential approaches for cancer therapy.
\end{abstract}

\section{Contents}

1. Introduction

2. Constituents of the tumor microenvironment as accomplices in tumor progression

Correspondence to: Dr Chong-Kui Sun, State Key Laboratory of Oral Diseases, West China Hospital of Stomatology, Sichuan University, No. 14, Sec. 3, Renmin South Road, Chengdu, Sichuan 610041, P.R. China

E-mail: cksun@scu.edu.cn

*Contributed equally

Key words: tumor microenvironment, stromal cell, metastasis, cancer therapy
3. Factors mediating the 'prison break' of tumor cells

4. Processes mediating the 'prison break' of tumor cells

5. Therapeutic implication

6. Conclusion

\section{Introduction}

Tumorigenesis is a complicated and multistep process, in which successive mutations in oncogenes and tumor-suppressor genes virtually result in enhanced proliferation and resistance to cell death. Most human tumor types share various hallmarks, which include sustainment of proliferative signals, evasion of growth suppressors, resistance to cell death, replicative immortality, induction of angiogenesis, activation of invasion and metastasis, energy metabolism, evasion of immune destruction, genome instability and mutation, and tumorpromoting inflammation $(1,2)$. During the past decades of cancer research, our focus on cancer research has shifted from the malignant cancer cell itself to the tumor microenvironment and the complex interactions. The tumor microenvironment, which consists of resident fibroblasts, endothelial cells, pericytes, leukocytes and extracellular matrix, also contributes to the progression of cancer (3).

Studies have provided some evidence that human tumors are more than a mass of accumulating malignant cancer cells. Actually, tumor cells can efficiently recruit stromal cells (4), immune cells (5) and vascular cells (6) by secreting stimulatory growth factors, chemokines and cytokines. In turn, these recruited cells release growth-promoting signals and intermediate metabolites as well as remodel tissue structure to build the microenvironment. The reciprocal communication between cancer cells and the microenvironment eventually leads to enhanced proliferation and metastatic capability, and finally death.

As the tumor microenvironment actively participates in tumor progression and metastasis rather than acting as a by-stander, therapeutic strategies targeting the tumor microenvironment hold great potential. It is known that non-tumor cells are presumably and genetically more stable than tumor cells, thus, therapies targeting the tumor microenvironment are less likely to cause adaptive mutations and rapid metastasis. Yet, considering the complex interactions (stromal cells can both promote and inhibit tumor cell growth), therapies targeting the 
tumor microenvironment for cancer therapy should be highly selective. Therefore, further studies must provide new insight into the tumor microenvironment for better cancer therapeutic strategies. We will review how tumor cells recruit stromal cells to the primary tumor site and build the microenvironment. Moreover, we will highlight the role of the tumor microenvironment in the regulation of tumor progression and discuss the potential value for cancer therapy.

\section{Constituents of the tumor microenvironment as accomplices in tumor progression}

A tumor is a highly complex tissue composed of neoplastic and stromal cells. It is widely known that stromal cells contain a variety of mesenchymal cells, particularly fibroblasts, myofibroblasts, endothelial cells, pericytes and inflammatory cells associated with the immune system. Accumulating evidence has confirmed that tumor cells must recruit and reprogram the surrounding normal cells to serve as contributors to tumor progression. Tumor cells and the supporting normal cells form an organ-like structure and make concerted efforts for rapid proliferation, local invasion and metastases. These normal cells in the tumor microenvironment mainly consist of fibroblasts, immune cells and vascular cells. These cells are recruited to the primary tumor site and build the tumor microenvironment for tumor progression in soluble paracrine signals (Fig. 1).

Fibroblasts are recruited to the tumor microenvironment. Among the supporting cells, fibroblasts represent the majority of the stromal cells in various types of human cancers. Initially, activated fibroblasts inhibit the early stages of tumor progression (7), and this effect is carried out through simple gap junctions between fibroblasts and IL-6 production $(8,9)$. Fibroblasts can then be modulated by tumor cells and develop into cancer-associated fibroblasts (CAFs), which are identified by expression of different biomarks, such as $\alpha$-smooth muscle actin, vimentin, desmin and fibroblast-activation protein. Although research has made great contributions in this field, the original source of CAFs remains controversial. CAFs are critically involved in promoting growth and angiogenesis, remolding of the extracellular matrix (ECM) and directing cell-cell interaction (10). Clinical and experimental data indicate that tumor cells secrete a high level of transforming growth factor $\beta$ (TGF- $\beta$ ), which is strongly chemotactic for fibroblasts and transdifferentiates fibroblasts into CAFs $(11,12)$. The main source of CAFs is thought to be derived from normal fibroblasts through genetic alteration. It has been observed that expression of genes in fibroblasts may be altered via point mutation, loss of heterozygosis, and the number of gene copy changes. The mutation or inactivation of phosphatidylinositol-3,4,5-trisphosphate 3-phosphatase (PTEN) and p53 is frequently detected in CAFs around the primary tumor lesion (13). However, the evidence for genetic alterations as a factor to induce CAFs is still unconvincing. Normal dermal fibroblasts can also be orchestrated indirectly dependent on immune cells by carcinoma cells to express proinflammatory genes (14). Except for normal fibroblasts, CAFs are thought to be generated from epithelial cells, endothelial cells and, interestingly, cancer cells (Fig. 1). The myofibroblast, an essential cell type, participates in wound healing (15) and was also found to be a major source of CAFs (16). Laminin, which critically contributes to cell attachment and differentiation, is downregulated in myofibroblasts in cancer regions, providing an additional evidence that CAFs can be directly differentiated from myofibroblasts (17). In addition, vascular cells such as vascular smooth muscle cells show similar markers and morphology with myofibroblasts, providing another probability that CAFs may be derived from mural cells (18). Platelet-derived growth factor (PDGF) can also indirectly recruit myofibroblasts by stimulation of TGF- $\beta$ release from macrophages (19). Another potential source of CAFs is human bone marrow-derived mesenchymal stem cells (hMSCs). hMSCs, which are thought to be multipotent cells, are present in adult marrow and have the potential to differentiate into lineages of mesenchymal tissues (20). Under hypoxic conditions, tumor cells secrete IL- 6 and activate both Stat 3 and MAPK signaling pathways to enhance the migratory potential of hMSCs $(21,22)$. The recruited hMSCs have the potential to develop into CAFs. Notable, surrounding normal epithelial cells can be another source of CAFs by undergoing epithelial-to-mesenchymal transition (EMT) in response to stimuli from the microenvironment. A previous study reported that proliferating endothelial cells induced by TGF- $\beta$ can undergo a phenotypic conversion into fibroblast-like cells (23). Another recent study confirmed that EndMT (endothelial-tomesenchymal transition) frequently appears in a variety of cancers. Zeisberg et al found that endothelial cells are a source of CAFs by undergoing EndMT at the invasive front of tumors in transgenic mice (24). This suggests that EndMT is an important process for the accumulation of CAFs. Interestingly, CAFs can also be derived from cancer cells directly which shows dangerous signaling. Cancer cells are obstinate and are not eradicated easily. A previous study revealed that under the proper conditions, breast tumor cells can transdifferentiate into myoepithelial cells and finally become myofibroblasts, which are the ancestors of CAFs (25). Meanwhile, recent genetic analysis found that CAFs isolated from human breast tumor biopsies were indeed derived from epithelial cancer cells (26). However, genetic alterations present in both CAFs and cancer cells are not identical, suggesting that only a small part of stromal cells and cancer cells may share a common origin (27). Therefore, it is worthwhile to consider the consequences of tumor cell-derived CAFs in tumor progression, the indirect action of nonmalignant CAFs on associated tumor cells as a mechanism of facilitating tumor growth. The current paradigm would appear then to be that some CAFs encourage their neighbors to become more malignant rather than performing this function themselves.

Once CAFs are stimulated, they can secrete stromal cell-derived factor 1 (SDF-1), which recruits circulating endothelial progenitor cells (EPCs) into the tumor mass to stimulate angiogenesis (28). Importantly, a recent report shed new light on the roles of miRNAs in tumor microenvironment. Downregulation of miR-320 and upregulation of ETS2 (v-ets erythroblastosis virus E26 oncogene homolog 2, one of the direct targets of miR-320), were found to contribute to tumor angiogenesis and tumor-cell invasion in PTEN-deleted stromal fibroblasts (29). Another report revealed that CAFs mediate tamoxifen resistance through IL-6-induced degradation of ER- $\alpha$ in luminal breast cancer (30). This study demonstrated 


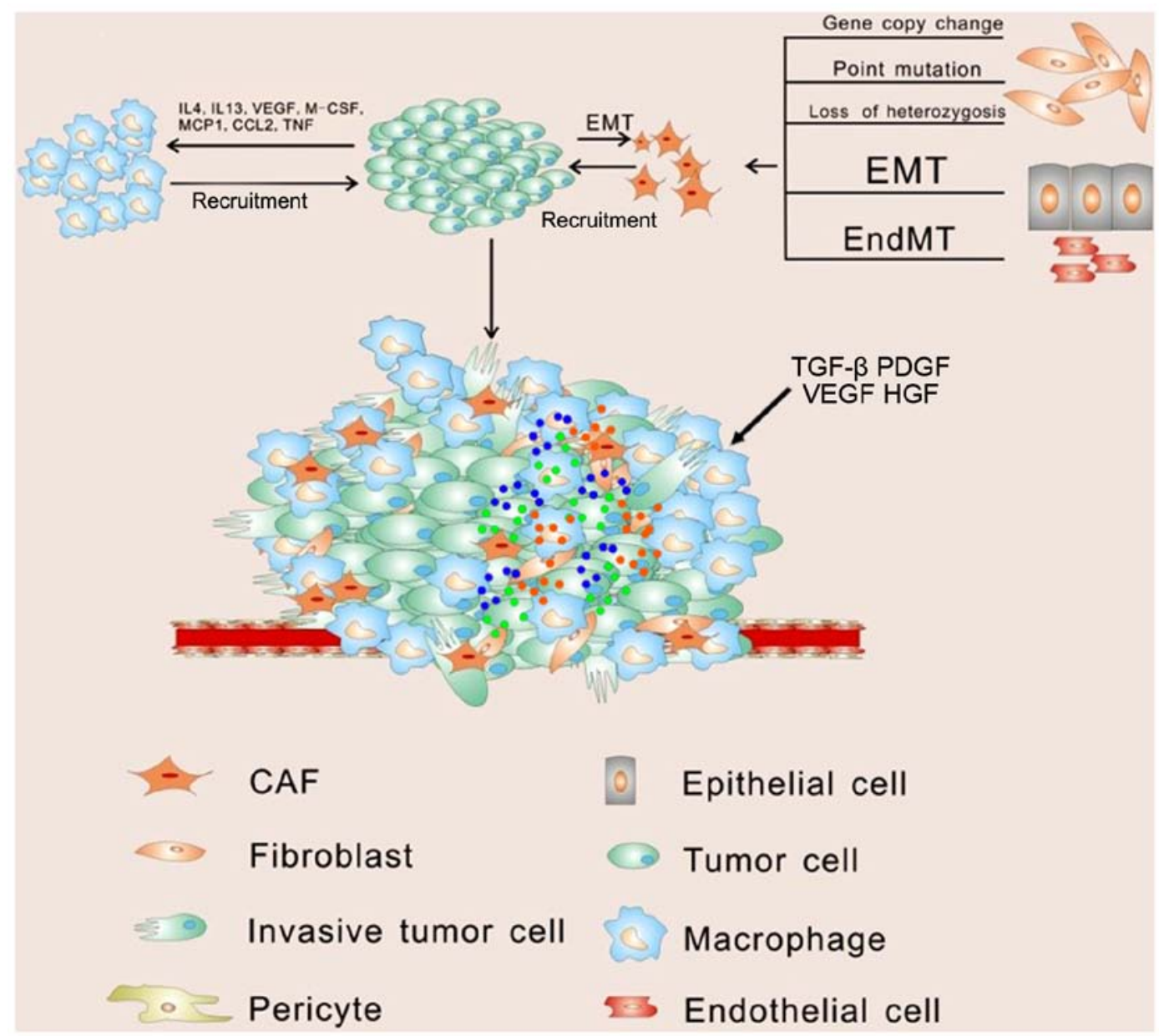

Figure 1. Formation of the tumor microenvironment. Construction of the tumor microenvironment and the detailed processes involved in the recruitment of various cell types are shown. The tumor cells recruit cancer-associated fibroblasts (CAFs), epithelial cells, fibroblasts, pericytes, macrophages and endothelial cells to the primary tumor site. VEGF, vascular endothelial growth factor; CCL2, chemokine chemokine (C-C motif) ligand 2; TNF, tumor necrosis factor; M-CSF, macrophage-colony stimulating factor; MCP-1, monocyte chemotactic protein 1 ; TGF- $\beta$, transforming growth factor $\beta$; PDGF, platelet-derived growth factor; HGF, hepatocyte growth factor; EMT, epithelial-to-mesenchymal transition; EndMT, endothelial-to-mesenchymal transition.

that CAFs also play a role in drug resistance. Studies designed to ascertain how CAFs provide a suitable tumor microenvironment may facilitate the development of new therapeutic strategies against tumor progression.

Immune cells are recruited to the tumor microenvironment. Oncogenic mutations and transcription factor activation induce high levels of inflammatory mediators, including cytokines and chemokines. Chemokines and cytokines are critical autocrine and paracrine factors in tumor development, which are secreted into the tumor microenvironment to recruit and activate various inflammatory cells. In turn, these 'educated' inflammatory cells produce more inflammatory signals and form a cancerrelated inflammatory microenvironment to induce cancer cell evasion from immune destruction. Finally these inflammatory cells promote tumor progression. Among these immune cells, macrophages represent the majority and play leading roles in cancer-related inflammation. Macrophages can polarize into two different types of macrophages upon different stimulation. Classically activated macrophages (M1), following exposure to interferon, have antitumor activity and elicit tissue destructive reactions. However in response to IL-4 or IL-13, macrophages undergo alternative activation (M2) (31). Tumor-associated macrophages (TAMs) closely resemble alternative (M2) macrophages, which produce high amounts of interleukin IL-10. Moreover, these cells exhibit anti-inflammatory and tissue repair functions (32). Vascular endothelial growth factor (VEGF), macrophage-colony stimulating factor (M-CSF) and monocyte chemotactic protein 1 (MCP-1) produced by tumor cells efficiently recruit macrophages to the tumor microenvironment by promoting migration and survival (33). Interestingly, a low level of MCP-1 induces modest monocyte infiltration resulting in tumor formation, whereas a high level is associated with massive monocyte/macrophage infiltration into the tumor mass, leading to tumor destruction (34). Experimental evidence suggests that signaling molecules produced by both tumor cells and these macrophages, work together to activate integrin $\alpha 4 \beta 1$, with subsequent stimulation of myeloid cells entering the tumor microenvironment (35). Among these signaling molecules, chemokine and chemokine receptors make up a complex network, which influence the development of primary tumors and metastases (36). Recent data showed that tumor cells and host organ-derived chemokine chemokine (C-C motif) ligand 2 (CCL2) recruit inflammatory monocytes, which differentiate into macrophages and facilitate efficient tumor cell metastasis seeding and growth in distant meta- 
static sites of the lung (37). CCL2 can also increase prostate tumor growth and bone metastasis through macrophage and osteoclast recruitment (38). These studies have made great contributions to our understanding of the microphage recruitment to the tumor site (Fig. 1). Cancer cells that overexpress chemokine (C-X-C motif) ligand 2 (CXCL1/2) can also attract

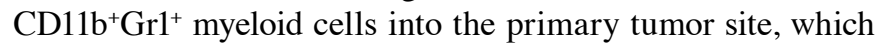
produce chemokines, including S100A8/9, that enhance cancer cell survival (39). CCL21, expressed by melanoma tumors, shifts the host immune response from immunogenic to tolerogenic, and facilitates tumor progression (40). Other soluble factors, such as prostaglandin E2 (PGE2) and TGF- $\beta$, also play an active role in facilitating tumor progression by limiting natural killer (NK) cells (41). Tumor necrosis factor (TNF) signaling can drive myeloid-derived suppressor cell accumulation, and promote tumor cell escape from the immune system (42). In a spontaneous murine model of patent ductus arteriosus (PDA), Bayne et al demonstrated that tumor-derived granulocyte-macrophage colony-stimulating factor (GM-CSF) drives the accumulation of $\mathrm{Gr}-1^{+} \mathrm{CD} 11 \mathrm{~b}^{+}$myeloid cells as part of the cancer-associated inflammatory reaction, which in turn suppresses antitumor $\mathrm{T}$ cell immunity and promotes tumor growth (43). In particular, CXCL12 can regulate cancer cell survival, proliferation and migration, and, indirectly, via angiogenesis or recruiting immune cells to affect tumor progression (44). These 'educated' immune cells work together with local tumor cells and CAFs to produce more inflammatory factors forming an inflammatory microenvironment and protecting tumor cells from immune destruction. Finally, this cooperation promotes tumor progression and metastasis. However, studies on the relationship between inflammation and cancer are sparse. Progress in the identification of inflammation-dependent mechanisms that affect tumor cell survival, trafficking and chemo-attractive functions are valuable to new drug development. Understanding of the biological and molecular mechanisms of carcinogenesis may provide more opportunities for clinical therapy.

Vascular cells are recruited to the tumor microenvironment. Tumors require the formation of a complex vascular network to meet the metabolic and nutritional needs for growth. Recent evidence suggests that endothelial cells and pericytes, which play essential roles in the 'turn on' of the angiogenic switch $(45,46)$, can also be modulated by tumor cells. Several studies indicate that VEGF is highly expressed in a variety of human tumors, including lung (47), breast (48), ovarian (49), bladder and kidney (50). VEGF elicits a pronounced angiogenic response in a variety of in vivo models. VEGF directly activates enterochromaffin cells (Ecs) through mitogenic and promigratory effects, and also mobilizes endothelial progenitor cells (EPCs) from the bone marrow, modulates EPC kinetics and promotes EPC differentiation (51). Interestingly, miR-126 regulates endothelial recruitment and metastatic colonization through IGFBP2, PITPNC1 and MERTK targeting (52). Protein kinase $\mathrm{C}(\mathrm{PKC})$ inhibition plays a crucial role in the extracellular signal-regulated kinase (ERK) phosphorylation that mediates proliferation of pulmonary vascular endothelial cells (53). Another important signaling pathway PI3K/AKT/mTOR (phosphatidylinositol 3-kinase/AKT/mammalian target of rapamycin) is activated in most human cancers and is closely related with the production of VEGF. It has been reported that VEGF secretion is increased both in hypoxia-inducible factor 1 (HIF-1)-dependent and -independent manners in response to PI3K/AKT activation (54). Activation of mTOR was detected in head and neck squamous cell carcinoma (HNSCC) patients with metastasis and inhibition of mTOR decreased vascular formation and lymph node metastasis $(55,56)$. Inhibitors targeting signaling and molecules involved in angiogenesis may be a viable strategy for the treatment of cancer.

\section{Factors mediating the 'prison break' of tumor cells}

Growth-promoting signals. Growth-promoting signals in the microenvironment play a critical role in both normal and pathological tissues. Normal tissues require that growth factors be induced from a quiescent state into an active proliferation state. They tightly control the production and the release of growthpromoting signals that instruct themselves or the entry of other cells into the cell growth and division cycle. At the same time, growth-promoting signals contribute to cancer-sustaining proliferation, which has been confirmed as a hallmark of cancer. Cancer cells obtain growth signals through autocrine and paracrine pathways. Analyzing previous research, we conclude that tumor stromal cells provide cancer cells with growth-promoting signals, including growth factors, cytokines and chemokines. Table I lists these various tumor-promoting molecules.

Growth factors, secreted by stromal cells into the microenvironment, promote tumor progression via stimulation of cellular growth, proliferation and cellular differentiation. For instance, TGF $\beta$ is known to enhance EMT and invasiveness in primary carcinomas (57). Blocking the TGF $\beta$ signaling pathway can reduce intravasation and metastatic seeding in the lung as well as bone (58-62). A recent report by Labelle et al suggests that platelets secrete TGF $\beta$-1 to activate the TGF $\beta /$ Smad pathway in tumor cells, and enhance invasiveness and metastasis (63). Hepatocyte growth factor (HGF), which was originally cloned as a mitogenic protein in hepatocytes (64), can specifically activate MET receptor tyrosine kinase as well as stimulate mitogenesis, cell motility and matrix invasion $(65,66)$. Two studies found that the higher a patient's HGF level, the less likely he/she was to remain in remission. The study found that stromal cells secreted HGF resulting in activation of the MET, reactivation of the mitogen-activated protein kinase (MAPK) and phosphatidylinositol-3-OH kinase (PI3K)-AKT signaling pathways. These cellular signaling changes in tumor cells immediately induce resistance to RAF inhibition and confer resistance to BRAF inhibitor in BRAF-mutant melanoma cells $(67,68)$. In addition to chemical inhibitors for the inhibition of growth factors, antibodies that target receptors have been developed. Cetuximab, an EGFR monoclonal antibody, acts as an efficient antitumor drug in many types of cancer. The efficiency of cetuximab against chemo- or radio-resistant HNSCC was demonstrated (69). Other growth factors secreted by stromal cells can also promote cancer cell growth. For instance, VEGF, PDGF, bFGF and IGF1 can facilitate tumor progression by stimulating angiogenesis (Table I).

In addition to growth factors, chemokines are also important for enhancing tumor growth. Chemokines are chemotactic cytokines, which are induced by inflammatory cytokines, 
Table I. Summary of tumor-promoting molecules.

\begin{tabular}{|c|c|c|}
\hline Name & Main function & References \\
\hline OPN & $\begin{array}{l}\text { Tumor metastasis, protection from apoptosis, induction of tumor-associated } \\
\text { inflammatory cells }\end{array}$ & $(204-207)$ \\
\hline Galectin-3 & Neoplastic transformation, tumor metastasis & $(208,209)$ \\
\hline VEGF & Stimulates angiogenesis, regulates vascular permeability & $(210)$ \\
\hline EGF & Promotes cancer growth, contributes to aggressive behavior & $(75,211)$ \\
\hline TGF $\beta$ & Enhances EMT and invasiveness, regulates inflammation & $(57,212)$ \\
\hline $\mathrm{HGF}$ & Angiogenesis, tumorigenesis, tissue regeneration, tumor metastasis & $(65,66,213)$ \\
\hline Histamine & Increases vascular permeability, pro-inflammatory & $(214)$ \\
\hline $\mathrm{TP}$ & Angiogenesis, chemotherapy activation, promotes tumor growth & $(215,216)$ \\
\hline BDNF & Tumorigenesis & $(217)$ \\
\hline P-selectin & Promotes tumor growth, tumor metastasis, pro-inflammatory & $(218)$ \\
\hline LPA & Survival, cell proliferation, migration, tumor metastasis & (219) \\
\hline S1P & Survival, vascular permeability, cell invasion & $(220)$ \\
\hline Prothrombin & Tumor metastasis, tumor progression & $(221)$ \\
\hline PDGF & Angiogenesis, enhances stromal cell survival, proliferation and migration & (213) \\
\hline bFGF & Angiogenesis, mitogenic, tumor progression & (213) \\
\hline SERPINE1 & Angiogenesis, tumor invasion & $(222)$ \\
\hline IGF1 & Angiogenesis, mitogenic, tumor progression & $(213)$ \\
\hline ANGPT1 & Angiogenesis, tumor progression & (223) \\
\hline CCL2 & $\begin{array}{l}\text { Tumor growth and progression, promotes cancer growth, tumor metastasis, } \\
\text { tumor macrophage infiltration }\end{array}$ & $(76-78,224)$ \\
\hline CCL3 & Angiogenesis, tumor metastasis & $(225)$ \\
\hline CCL5 & Tumor growth and progression, recruits leukocytes during inflammation & $(224,226)$ \\
\hline CCL6 & Tumorigenesis, tumor metastasis & $(227)$ \\
\hline CXCL8 & Angiogenesis, leukocyte chemoattractant, pro-inflammatory & (228) \\
\hline CCL18 & Tumor progression, tumor metastasis & $(161)$ \\
\hline CCL21 & Tumor progression, tumor survival and invasion & $(40)$ \\
\hline CCL22 & Tumor progression, cell migration, tumor metastasis & $(229)$ \\
\hline CXCL1 & Promotes cancer growth, angiogenesis, cancer chemoresistance, tumor metastasis & $(39,74,230,231)$ \\
\hline CXCL2 & Tumor growth and progression, angiogenesis, cancer chemoresistance, tumor metastasis & $(230-233)$ \\
\hline CXCL3 & Tumor growth and progression, angiogenesis, tumor metastasis & $(224,230,231,234)$ \\
\hline CXCL5 & Angiogenesis, tumor metastasis & $(230,231,235,236)$ \\
\hline CXCL6 & Angiogenesis, tumor metastasis & $(230,231,237,238)$ \\
\hline CXCL7 & Angiogenesis, tumor metastasis & $(230,231,239)$ \\
\hline CXCL8 & Tumor growth and progression, angiogenesis, tumor metastasis & $(224,231)$ \\
\hline CXCL12 & Tumor progression, tumor invasion and metastasis & $(240-242)$ \\
\hline
\end{tabular}

OPN, osteopontin; VEGF, vascular endothelial growth factor; EGF, epidermal growth factor; TGF $\beta$, transforming growth factor- $\beta$; HGF, hepatocyte growth factor; TP, thymidine phosphorylase; BDNF, brain-derived neutrophic factor; LPA, lysophosphatidic acid; S1P, sphingosine 1-phosphate; PDGF, platelet-derived growth factor; bFGF, basic fibroblast growth factor; SERPINE1, serpin peptidase inhibitor (also known as plasminogen activator inhibitor-1, PAI1); IGF1, insulin-like growth factor 1; ANGPT1, angoipoietin 1; CCL, C-C motif chemokine; CXCL5, C-X-C motif chemokine.

growth factors and pathogenic stimuli (70-72). Chemokine signaling plays a major role in cellular transformation, inflammation, and wound healing; as well as tumor growth, angiogenesis, tumorigenesis and metastasis (73) (Table I). Currently, the research of cancer-associated chemokines has mainly focused on CXC chemokines and CC chemokines. Some CXC chemokines promote cancer development mainly by promoting angiogenesis and enhancing tumor metastasis. CXCL1, a small cytokine belonging to the
CXC chemokine family, is overexpressed in $70 \%$ of human melanomas and is involved in CRC tumor growth and angiogenesis (74). Overexpression of CXCL1/2 in cancer cells attracts $\mathrm{CD} 11 \mathrm{~b}^{+} \mathrm{Gr}^{+}$myeloid cells to the primary tumor site, and finally, enhances the viability of cancer cells through S100A8/9 factors (39). The subset of CC chemokine families, which are secreted by stromal cells have multiple functions in the progression of cancer. For example, CCL2 released from stromal cells can promote tumor growth, facilitate macro- 
phage infiltration and induce metastasis (75-78). Meanwhile, other molecules, such as osteopontin (OPN), galectin-3 and brain-derived neutrophic factor (BDNF), are also involved in the tumor microenvironment and promote cancer progression. Furthermore, some molecules in the vasculature, such as LPA, $\mathrm{S} 1 \mathrm{P}$, and prothrombin, play crucial roles in tumor development (Table I).

Small and non-coding RNAs (miRNAs) post-transcriptionally control the translation and stability of mRNAs. These RNAs participate in the regulation of metabolism and tumorigenesis (79-81). RNAs cannot function as extracellular signaling molecules because they are vulnerable to be degraded by ribonucleases (82). But interestingly, recent evidence shows that miRNAs contained in exosomes act as signal transducers and play important roles in the tumor microenvironment acting as a bridge between cancer cells and stromal cells (82-85). Kosaka et al showed that miR-143 expression in normal prostate cells was higher and transferred growth-inhibitory signals to prostate cancer cells both in vitro and in vivo. They highlighted that secretory tumor-suppressive miRNAs may be a death signal from winners to losers in the context of cell competition (85). Macrophages also regulate the invasiveness of breast cancer cells through exosome-mediated delivery of oncogenic miRNAs (86). Notably, tumor-secreted miR-21 and miR-29a also can function by an unexpected mechanism, by binding as ligands to receptors of the Toll-like receptor (TLR) family, murine TLR7 and human TLR8 in immune cells, triggering a TLR-mediated prometastatic inflammatory response that ultimately may lead to tumor growth and metastasis (87). However, the detailed mechanisms of the role of secretory miRNAs in the tumor microenvironment are still poorly understood. Some studies only report that microRNAs can be stable blood-based markers for cancer detection. For example, a significant increase in miR10b, miR34a and miR155 concentrations in the peripheral blood of breast cancer patients and the observed correlation with tumor progression suggest a potential clinical utility of circulating miRNAs as a new class of future biomarkers (88). Serum levels of miR-141 (an miRNA expressed in prostate cancer) can distinguish patients with prostate cancer from healthy controls, and may be used as an important approach for the blood-based detection of human cancer (89). Although the understanding of the role of miRNAs in the tumor microenvironment remains poorly understood, it has been proposed that miRNAs in the tumor microenvironment may potentially serve as paracrine signaling molecules having both tumor-promoting as well as tumor-suppressing effects.

Buffering metabolic stress. Over the past 10 years of cancer research, the reprogramming of energy metabolism has been considered as a hallmark of cancer. Metabolic reprogramming is always considered to be intrinsic to cancer cells, such as oncogene activation, inactivation of tumor-suppressor genes as well as the mutation of glycolytic enzymes (90). Yet, recent research has shifted our focus on the regulation of the tumor microenvironment in tumor metabolism. Compared with normal differentiated cells, cancer cells mainly rely on aerobic glycolysis rather than mitochondrial oxidative phosphorylation to gain the energy needs for rapid proliferation even under normal conditions, which is called the 'Warburg effect' (91) (Fig. 2). Yet, aerobic glycolysis is less efficient than oxidative phosphorylation for generating ATP; 4 mol ATP per mol glucose compared with 36 mol ATP per mol glucose when under oxidative phosphorylation. To meet the energy needs and high levels of glycolytic intermediates supporting anabolic reactions, tumor cells maintain enhanced glucose uptake through high levels of glucose transporters, lactate dehydrogenase and other glycolytic enzymes (92). Due to the high level of aerobic glycolysis, much lactate is generated by cancer cells, which contributes to an acidic condition, ROS production and MAPK signaling activation (93). High incidence of distant metastasis is related to the suppressed proliferation and cytokine production of human cytotoxic T lymphocytes $(94,95)$. But an elevated level of lactate accumulation in the tumor cells or the microenvironment also leads to an inhibitory effect of glycolysis and restriction of cell growth and proliferation. Tumor cells must secrete lactate into the surroundings via increased expression of lactate transporter monocarboxylate transporters 4 (MCT4). In response, MCT1 expression increases in CAFs resulting in the uptake of tumor-extruded lactate. CAFs increase the expression level of lactate dehydrogenase (LDH-B), resulting in the conversion of the influxed lactate to pyruvate. The pyruvate is shunted to the tricarboxylic acid cycle for ATP generation via oxidative phosphorylation, thereby satisfying the energy needs of the CAFs (96) (Fig. 2A). The released lactate can also be consumed by endothelial cells and stimulate angiogenesis through NF- $\mathrm{B} /$ IL-8 signaling (97). Interestingly, lactate produced by hypoxic tumor cells may indeed diffuse and be taken up by oxygenated tumor cells $(98,99)$. Sonveaux et al suggest that hypoxic tumor cells depend on glucose and glycolysis to produce energy and secrete lactate. The lactate is diffused along its concentration gradient and is taken up by oxygenated tumor cells and used to meet the energy needs (100). A previous study examined the expression of major proteins involved in cellular aerobic and anaerobic metabolism, PDH, PDK1, LDH1, LDH5, MCT1, MCT2 and GLUT1, between normal tissues, cancer cells and tumor-associated stromal cells. The results suggest that the newly formed stroma and vasculature express complementary metabolic pathways, buffering and recycling products of anaerobic metabolism to sustain cancer cell survival (101). Nieman et al provide strong evidence that adipocytes promote the initial homing of tumor cells to the omentum through adipokine secretion. Subsequently, adipocytes provide fatty acids to the cancer cells, fueling rapid tumor growth (102) (Fig. 2D). These studies highlight how tumors can survive and grow in hypoxia and an energy crisis. They are capable of organizing the regional stromal cells into a harmoniously collaborating metabolic domain living in 'the same boat'.

In addition to glucose, glutamine is the other molecule catabolized in appreciable quantities in most mammalian cell in vitro cultures (103); metabolic profiling of the colon and stomach cancer microenvironment by capillary electrophoresis time-of-flight mass spectrometry identified a significant accumulation of all amino acids except glutamine in the tumors (104) (Fig. 2F). CAFs undergo an autophagic program, leading to the generation and secretion of high glutamine levels into the tumor microenvironment to meet the glutamine needs of cancer cells. Cancer cells accumulate glutamine and convert it to glutamate which is further catabolized to $\alpha$-ketoglutarate, 


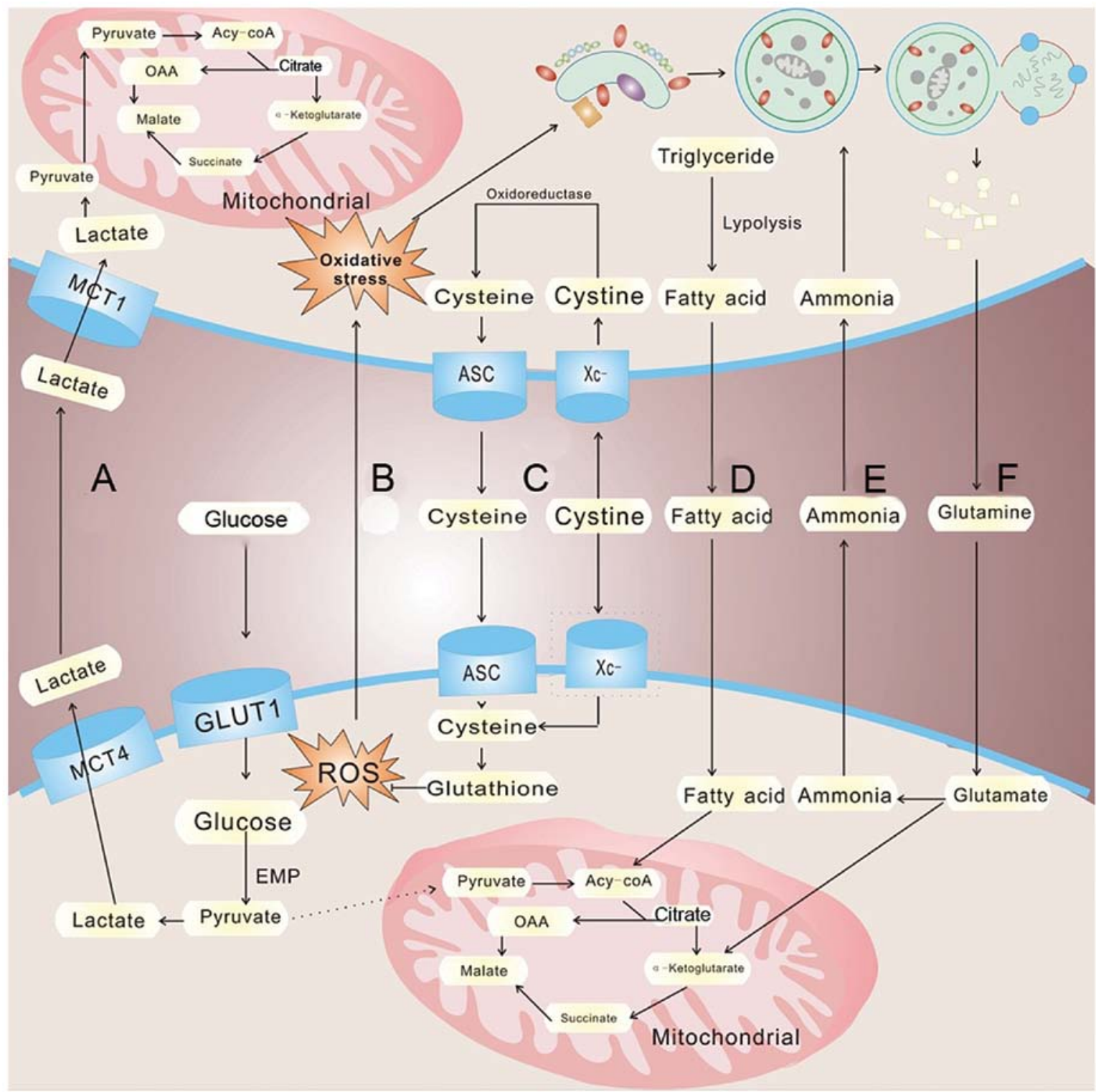

Figure 2. Summary of the role of the tumor microenvironment in the regulation of cancer cell metabolism. (A) Tumor cells, under hypoxic conditions, secrete lactate via MCT4. In response, cancer-associated fibroblasts (CAFs) and oxygenated tumor cells take up the tumor-extruded lactate. (B) Cancer cells induce ROS production in CAFs, leading to the onset of stromal oxidative stress, which in turn, drives autophagy and provides recycled nutrients via catabolism and aerobic glycolysis to feed the appetite of adjacent cancer cells. (C) Tumor stromal cells are able to take up cystine, convert it to the amino acid cysteine, and then secrete it. Tumor cells then use cysteine to produce glutathione, resulting in increased ROS resistance and survival. (D) Adipocytes provide tumor cells with fatty acids supplying the energy needs of rapid tumor growth. (E) Glutamine can be hydrolyzed as ammonia in tumor cells and reused by CAFs. (F) CAFs secrete glutamine into the tumor microenvironment to meet the glutamine needs of the cancer cells. MCT4, monocarboxylate transporter 4; GLUT1: Glucose transporter 1; ASC: Neutral amino acid transporter A; Xc-: Cystine/glutamate transporter; ROS: Reactive Oxygen Species; OAA: Oxaloacetate.

enters the TCA cycle and increases the mitochondrial activity of cancer cells. The by-product, ammonia, freely diffuses into the microenvironment, and then induces autophagy and glutamine production in CAFs, which confirm a cascade between CAFs and cancer cell interactions (105) (Fig. 2E). Not only can glutamine be used in the TCA flux to meet the energy needs of cancer cells, but is also involved in the synthesis of non-essential amino acids alanine, serine, arginine, and proline (106). Jain et al suggested a key role for glycine in rapid cancer cell proliferation using metabolic profiling approaches. Interestingly, they found that rapidly proliferating non-transformed cells, including human bronchial epithelial cells and lymphocytes, release rather than consume glycine (107). These reports found that normal cells near tumor cells may provide glycine for the rapid proliferation of cancer cells. Treatments that target tumors and surrounding cells should be considered, rather than targeting only the tumor cells. This concept may provide us with novel strageties for tumor treatment.

Cellular metabolism is critical for the generation of energy in biological systems, however, as a result of electron transfer reactions, reactive oxygen species (ROS) are generated in aerobic cells. ROS and cellular oxidant stress have long been associated with cancer (108-111). Previous evidence suggests that cancer cells normally produce a higher ROS level than normal cells (112). Hypoxia, mitochondrial dysfunction, and inflammation, ionizing radiation, chemotherapeutic agents, hyperthermia, inhibition of antioxidant enzymes, or depletion of cellular reductants such as NADPH and glutathione, can 
all lead to the accumulation of ROS in cancer cells $(113,114)$. Although a low level of ROS is easily managed by cancer cells, abnormally high levels of ROS induce oxidative stress. A low level of ROS promotes cell proliferation and differentiation, while a high level of ROS can cause oxidative damage to lipids, proteins, DNA and finally cause cell death (115). Recent evidence highlights the role of ROS in the tumor microenvironment and provides new insight into metabolic associations between cancer cells and non-malignant neighbors in the stroma. Accumulated ROS are dispersed from cancer cells to adjacent fibroblasts (116), leading to the oxidative stress of stromal cells, which, in turn, drives autophagy via $\mathrm{HiF} 1$ induction and $\mathrm{NF}-\kappa \mathrm{B}$ activation; meanwhile providing recycled nutrients via catabolism and aerobic glycolysis to feed the appetite of adjacent cancer cells. In addition, stromal ROS production induced by cancer cells leads to local DNA damage as well as DNA damage in adjacent cancer cells via a 'bystander effect'. As a consequence, stromal ROS promote aneuploidy and genomic instability in cancer cells, driving tumor-stroma coevolution. These studies proposed a simple solution to the autophagy paradox [both promote cell death and survival (117-119)], which is called 'The Autophagic Tumor Stroma Model of Cancer' (120-126). In this simplistic model, it is proposed that autophagy acts as a tumor suppressor when it occurs in epithelial cancer cells; conversely, autophagy acts as a tumor promoter when it occurs in CAFs. Zhang et al provide another mechanism of tumor-stroma interactions to avoid ROS accumulation in cancer cells. They showed that bone marrow stromal cells can expressed a high level of Xc- transporter and effectively take up cystine to synthesize GSH (127). It is known that a high level of cellular GSH can both release oxidative stress and promote cell survival. Metastatic stress and ROS both are crucial for tumor survival and growth. It is important for us to understanding how tumor cells conquer the energy crisis and oxidative stress. When we discuss invasion and metastasis, it must be remembered that tumor cells have accomplices.

\section{Processes mediating the 'prison break' of tumor cells}

Induction of angiogenesis. Like normal tissues, tumors need to sustain a nutrient supply and evacuate metabolic wastes. Blood vessels nourish nearly every organ of the body, and deviations from normal vessel growth can contribute to numerous diseases. Angiogenesis allows tumors to obtain nutrients and evacuate metabolic waste with no difficulty (128). Tumorassociated angiogenesis is currently known as a hallmark of cancer. It is now widely accepted that the 'angiogenic switch' is under the tight control of pro-angiogenic molecules and anti-angiogenic molecules, and the 'angiogenic switch' is on only when the net balance between pro-angiogenic molecules and anti-angiogenic molecules is tipped in favor of angiogenesis (128-130). Mounting evidence suggests that stromal cells in the tumor microenvironment play critical roles in switching on and sustaining chronic angiogenesis in many tumor types. Among the various types of stromal cells, TAMs are one of the most important cell types involved in promoting tumor-associated angiogenesis. Leek et al found that the number of TAMs is positively correlated with tumor angiogenesis in breast carcinomas (131). Subsequent studies have confirmed such a link in a wide array of tumor types. TAMs can induce angiogenesis through different pathways, which can be divided into three categories. First, TAMs release pro-angiogenic factors directly activating endothelial cells. In early 1984, TAMs were demonstrated to be potent stimulators of neovascularization and endothelial cell proliferation, and that depletion of macrophages from tumor cell suspensions significantly decreased their angiogenic potential (132). VEGF, bFGF, TGF- $\alpha / \beta$, EGF and IL-1 $\beta$ secreted by macrophages control tumor angiogenesis (133-138). These factors induce endothelial cell activation and differentiation into tumor neovessels. Recently, Chen et al confirmed that M2 phenotype macrophages can promote angiogenesis in a paracrine manner via the endothelial nitric oxide synthase (eNOS) signaling pathway (139). Additionally, TIE2expressing macrophages (TEMs) can directly interact with ECs, is important for tumor angiogenesis and can be targeted to induce effective antitumor responses (140). Secondly, TAMs recruit other pro-angiogenic cells. TAMs can attract mononuclear macrophages (MONO) and TEMs into the tumor microenvironment. Recruited TEMs can also recruit endothelial and myeloid progenitors capable of directly incorporating into the tumor vasculature (141). Thirdly, TAMs modulate ECM. Matrix metalloproteinases, which are ECM remodeling enzymes, regulate signaling pathways that control cell growth, inflammation and angiogenesis. Mounting evidence suggests that TAMs also produce and secrete MMP2, MMP7, MMP9 and MMP12 to the tumor microenvironment (142-144). These MMPs can interact with ECM and increase the bioavailability of pro-angiogenic factors, including VEGFA and bFGF and promote angiogenesis.

Other cells, such as CAFs, can also promote angiogenesis. Guo et al showed that myofibroblasts express VEGFA and other angiogenic factors leading to the promotion of angiogenesis (145). Additionally, ovarian cancer-associated fibroblasts not only promote angiogenesis, but also lymph angiogenesis (146).

Activation of invasion and metastasis. Tumor metastasis always consists of a series of discrete biological processes that move tumor cells from the primary neoplasm to a distant organ. This process involves local invasion, intravasation, survival in the circulation, arrest at a distant organ site, extravasation, micrometastasis formation, and then metastatic colonization, and finally clinically detectable macroscopic metastases are formed (147-149) (Fig. 3). These events have been considered to be induced by genetic and/or epigenetic alterations within tumor cells, but accumulating evidence supports that tumor metastasis is also mediated by tumor stromal cells. Recent publications have confirmed that the tumor microenvironment contributes to every stage of tumor metastasis. Once the tumor cells need to escape from the primary tumor, they must interact with preexisting host basement membranes and the ECM (Fig. 3A). In early 1986, Liotta et al proposed a three-step hypothesis describing the sequence of biochemical events during tumor cell local invasion: i) tumor cell attachment via cell surface receptors which specifically bind to components of the matrix, ii) secretion of hydrolytic enzymes and iii) tumor cell locomotion into the region of the matrix $(150,151)$. MMP-7 expressed by breast epithelial cancer cells not only cleaves matrix components 


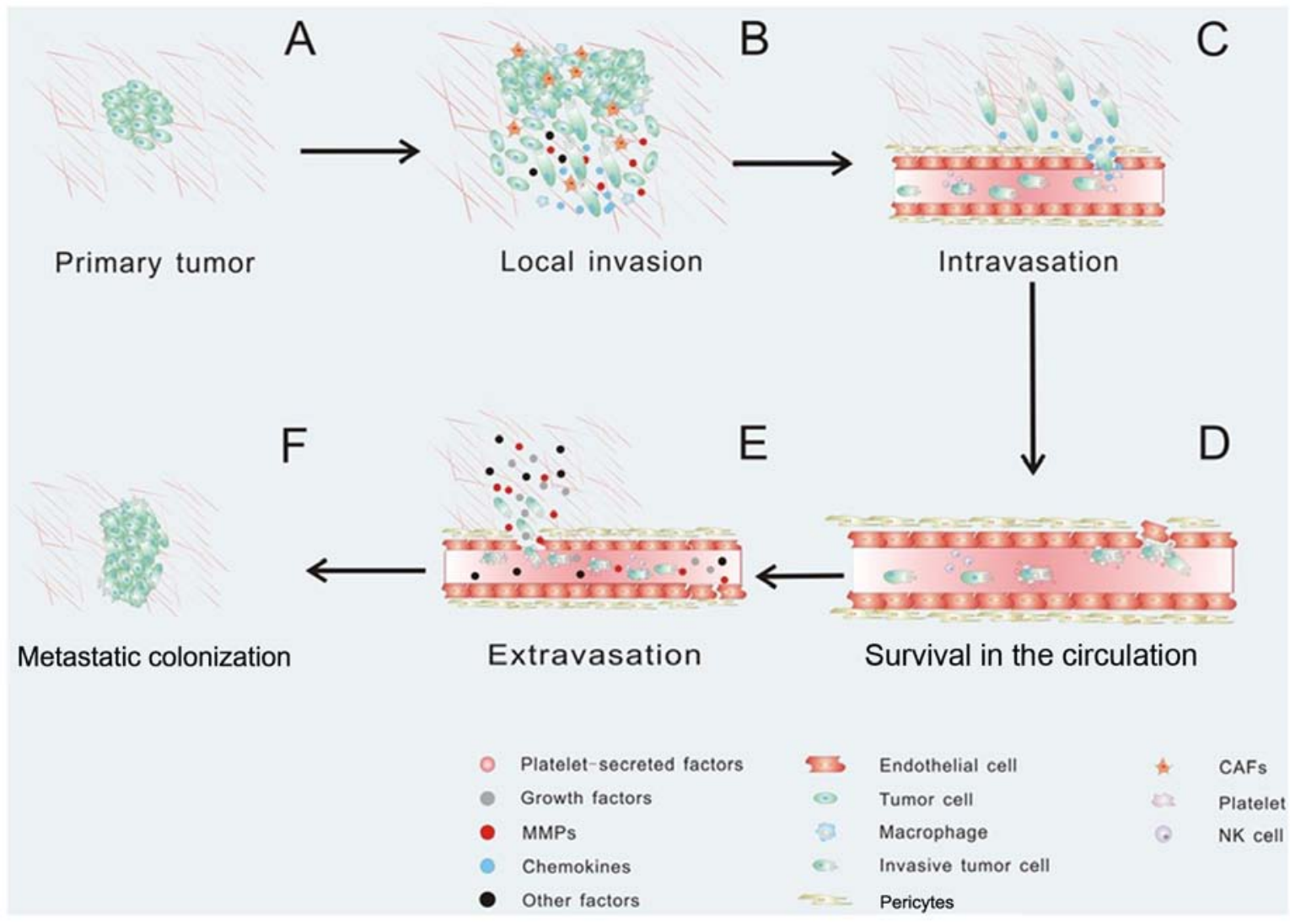

Figure 3. The tumor microenvironment regulates cancer metastasis and contributes to every stage of tumor metastasis. (A-F) A detailed summary of the role of the microenvironment in the metastasis of tumor is provided in the text. In brief, firstly, the primary tumor can invade to the surrounding tissue and then invade into the vascular. Secondly, these successfully invasive tumor cells must survive in the circulation system. Finally, the surviving tumor cells can extravasate to a new site and virtually carry out metastastic colonization. CAFs, cancer-associated fibroblasts; NK cell, natural killer cell; MMPs, metalloproteinases

in the tumor microenvironment, but also cleaves the cell surface adhesion molecule E-cadherin, leading to disruption of basement membrane structures and breast epithelial cell-cell junctions $(152,153)$. It has been confirmed that CAFs and macrophages promote cancer cell invasion by secreting matrix metalloproteases which cause proteolysis of the ECM leading to the promotion of cancer cell invasion (154-156). Fibroblasts also facilitate tumor cell invasion through force- and protease-mediated ECM remodeling (157-159), and intrinsic fibroblast caveolin-1 enhances tumor cell invasion by force-dependent remodeling of the surrounding environment via Rho GTPase activation (160). Activated macrophages and TAMs produce CCL18 and promote the invasiveness of breast cancer cells via the functional receptor for CCL18, PITPNM3 (161) (Fig. 3B). Interestingly, the ECM in the path of the invading cell can be remodeled by invadopodia (162), which are actin-rich membrane protrusions with a matrix degradation activity formed by invasive carcinoma cells (163). Podosomes, which are similar to invadopodia in molecular composition with ventral membrane protrusions and invaginations formed by macrophages and other type of cells (164-166), are proposed to play a role in ECM remodeling and then promote carcinoma cell invasion. For example, v-src-transformed 3Y1 rat fibroblast (3Y1-src) cells cultured on fibronectin degrade the fibronectin mainly at the podosomes, which is thought to underlie the invasive phenotype of 3Y1-src cells (167). Yamaguchi et al showed that macrophage podosomes have a matrix degradation activity and that colony-stimulating factor-1 (CSF-1) regulates the formation and organization of macrophage podosomes (162). These observations highlight the critical role of these specialized protrusive structures, invadopodia and podosomes, in tumor invasion (Fig. 3B). EMT is a hypothesized program of development of biological cells characterized by loss of cell adhesion, repression of E-cadherin expression, and increased cell mobility. EMT is essential for numerous developmental processes including mesoderm formation and neural tube formation and is regulated by many transcription factors, including zinc finger protein snail 1 (SNAI1), SNAI2, zinc finger E-box-binding homeobox 1 (ZEB1), ZEB2, TWIST, FOXC1 (forkhead box protein 1), FOXC2, TCF3 (transcription factor 3 - also known as E47), and GSC (homeobox protein goosecoid) (168). During tumor cell invasion, tumor cells co-opt EMT and the basement membrane becomes fragmented. The tumor cells can intravasate into lymph or blood vessels, allowing their passive transport to distant organs (169). It has been reported that tumor-associated fibroblasts (TAFs) induce the significant overexpression of FGFR4 in colorectal cancer cell lines and play a critical role in colorectal cancer EMT and metastasis (170). The stromal cells also stimulate EMT and promote tumor cell invasion. Pericytes, associated with endothelial cells, promote tumor angiogenesis, and 
promote tumor progression $(171,172)$. By using genetic mouse models or pharmacological inhibitors, Cooke et al showed that pericyte depletion suppressed tumor growth but resulted in hypoxia-associated EMT (173). Meanwhile, inflammation plays an important role in inducing EMT. Snail, which plays an essential role in inducing EMT and cancer metastasis by repressing expression of E-cadherin (174-176), can be stabilized by the inflammatory cytokine TNF $\alpha$ through the activation of the $\mathrm{NF}-\kappa \mathrm{B}$ pathway (177). It has been revealed that EMT is a dynamic process controlled by an inflammatory microenvironment.

After local invasion, the tumor cells infiltrate into the vascular spaces and establish direct contact with the blood. In this step, the tumor cells invade across the endothelial basal lamina and migrate between the endothelial cells lining the capillaries that service the tumor (178). Intravasation is always critical and is the rate limiting step of tumor metastasis $(148,179)$. Recent evidence suggests that the tumor microenvironment can promote cancer cell intravasation and metastasis. For instance, CCL2-expressing tumor cells attract monocytes and activate endothelial cells through CCR2, showing that a tumor cell-derived chemokine induces vascular permeability and enables efficient tumor cell intravasation (37,180) (Fig. 3C). In particular, platelets influence vascular integrity and play an important part in tumor metastasis (181). Notably, platelets secrete TGF $\beta 1$ to activate the TGF $\beta /$ Smad pathway, which synergize with the NF- $\kappa \mathrm{B}$ pathway, and enhance invasiveness and promote metastasis (63). When cancer cells enter the circulation system, most of the cancer cells will not survival due to the loss of integrin-dependent adhesion to ECM components causing anoikis, damage incurred by hemodynamic shear forces and the predation by cells by the innate immune system, specifically NK cells (149) (Fig. 3D). The circulating tumor cells can be detected in the bloodstream of patients using microchip technology, immunomagnetic nanoscreening and 2-NBDG fluorescence imaging (182-184). In order to survive in the circulation, tumor cells recruit platelets which, in turn, form a coat to protect them from the innate immune system. Even if tumor cells are NK susceptible and cytotoxic NK cells threaten their life in the blood, platelets are capable of protecting them from cytolysis by forming a physical shield around cancer cells, thereby promoting metastasis $(185,186)$. As platelets become activated, they can release growth factors, chemokines and protease, which can perpetuate the cohesion of heteroaggregates containing tumor cells. Platelets can also support the attachment to the endothelium and thereby contribute to metastasis (181) (Fig. 3D). During circulation, these invasive tumor cells may arrest at any distant organ site. When the new site is ready for metastatic tumor growth, the primary tumors are able to secrete factors to induce cancer cell extravasation. For example, the secreted angiopoietin-like-4 (Angptl4), as well as EREG, COX-2, MMP-1, and MMP-2, are able to disrupt pulmonary vascular endothelial cell-cell junctions to facilitate cancer cell extravasation $(59,187)$. When cancer cells arrive at a secondary site, the microenvironment is phenotypically and functionally distinct from the primary tumor, which may cause some physical barriers. In order to overcome physical barriers at the secondary site, primary tumors can secrete factors that perturb the distant microenvironment (Fig. 3E). For example, the pre-metastatic niche referred to as interactions between metastatic tumor cells and their stromal cells (188), have been defined as a new concept, which describes the tumor microenvironment playing important roles in the tumor cell survival in the circulation and growth at a secondary site. Primary tumors can secrete growth factors priming certain tissues in the metastatic site for tumor cell engraftment and growth (189). The primary tumor cells secrete pro-inflammatory factors such as VEGF-A, TGF $\beta$ and TNF $\alpha$ inducing the expression of chemoattractants S100A8 and S100A9 in lung VE-cadherin ${ }^{+}$endothelial cells and $\mathrm{Macl}^{+}$myeloid cells $(190,191)$. But the exact mechanism by which these chemoattractants elicit cell accumulation is not known. Hiratsuka et al showed that serum amyloid A (SAA)3 induced in pre-metastatic lungs by S100A8 and S100A9 has an important role in the accumulation of myeloid cells and acts as a positive-feedback regulator for chemoattractant secretion. Meanwhile, SAA3 can stimulate NF- $\kappa \mathrm{B}$ signaling in a TLR4-dependent manner and facilitate metastasis (192). More interestingly, Kaplan et al found that bone marrowderived hematopoietic progenitor cells that express vascular endothelial growth factor receptor 1 home to tumor-specific pre-metastatic sites and form cellular clusters before the arrival of tumor cells (193). They first demonstrated that a nonneoplastic cell population can portend a future metastatic site. After extravasation, tumor cells utilize the microenvironment in the metastatic site and form a new tumor microenvironment supporting metastatic tumor growth (Fig. 3F).

\section{Therapeutic implication}

Cancer cells require an enormous variety of genetic changes to elicit tumorigenesis. The clinical therapy for many types of human cancers has mainly focused on the malignant cancer cell itself, and have made great achievements, yet cancer therapy still remain a great challenge. Currently, the most commonly used radiotherapy and chemotherapy strategies have serious side effects, such as destruction of the patient immune system, and patients rapidly develop therapeutic resistance. As described above, the tumor microenvironment commonly participates in tumor initiation as well as progression in many tumor types, providing us with the hope that therapeutic targeting of these events could be efficient for cancer therapy. Recent publications provide strong evidence that tumor stromal cells forming the tumor microenvironment contribute to chemoresistance. For example, CCR2 null host mice responded better than a control when treated with doxorubicin. This effect was induced because myeloid cells can be recruited to doxorubicin-treated tumors through a stromal CCL2/CCR2 chemokine/chemokine receptor axis leading to chemoresistance (194). Similarly, during treatment with platinum analogs, endogenous mesenchymal stem cells (MSCs) are activated and release polyunsaturated fatty acids which protect cancer cells against a range of chemotherapeutics (195). These outstanding findings show that the tumor microenvironment is a potent administrator of resistance to traditional cytotoxic therapies, mainly chemotherapy and radiotherapy, and reveal potential available targets to enhance chemotherapy efficacy in patients. Multitargeted approaches, in which tumor cells and the tumor microenvironment are simultaneously inhibited, have been developed in recent years. These multitargeted approaches 
have many advantages compared with traditional therapies. On the one hand, stromal cells in the tumor microenvironment are presumably genetically stable, while tumor cells are known to be genetically unstable. Therefore, it is less likely for cancer patients to accumulate adaptive mutations as well as rapidly acquire resistance to chemotherapy as well as radiotherapy. On the other hand, the tumor microenvironment has a certain similarity in diverse cancer types, thus one therapeutic target of the tumor microenvironment can be implicated in more than one type of cancer. Based on research of the tumor microenvironment, multiple technologies have been developed for the research of cancer, such as liquid biopsy (196) and in silico molecular biology (197). The liquid biopsy is used to analyze tumor DNA in urine for non-muscle invasive bladder cancer patients and provides a non-invasive approach for bladder cancer detection (198). The in silico biomarker profiling technology is used to identify GLUT4-specific inhibitors for cancer therapy (199). These results made valuable contributions for the personalized/precision medicine and hold great potential for personalized detection.

Due to these advantages, targeting the tumor microenvironment holds great potential for cancer therapy. There are many tumor-promoting factors in the tumor microenvironment, suggesting that inhibition of these tumor-promoting factors or destroying these signaling pathways can prevent the development of cancer. For example, tumors in a stroma xenograft model treated with the TGF- $\beta$ inhibitor exhibited a reduction in blood vessels (200). As enhancement of GSH synthesis in CLL cells is possibly a crucial mechanism by which stromal cells facilitate leukemia cell survival and drug resistance through providing cysteine (127), a strategy to destroy stromal protection of CLL cells by inhibiting the transporter to impact the uptake of cystine by stromal cells as well as act in concert with traditional drugs may be an efficient pathway to cure CLL. In addition, the remodeling of ECM can be regulated by many families of matrix-degrading enzymes such as heparanase, chymases, MMPs and tryptases (201). Inhibitors of these enzymes such as PI-88 [an inhibitor for heparanase (202)] may prevent the multistep pathway in the tumor microenvironment in order to treat cancer. However, some fragments of basement membrane collagen generated by MMP have endogenous effects as integrin-mediated suppressors of pathologic angiogenesis as well as tumor growth (203). This fact indicates that the delicate balance between the tumor-inhibitory and tumor-promotion functions of stromal cells should be considered. In addition, the normal function of stromal cells should not be destroyed following therapy. More research is needed to develop more efficient approaches to combat cancer.

\section{Conclusion}

This review highlights the evidence for the crucial role of the tumor microenvironment in tumor progression and metastasis. As noted, tumor initiation as well as progression are complex and multistep processes in which the tumor microenvironment may contribute to its success. In this dynamic progression, the tumor microenvironment can affect cancer cell proliferation as well as tumor metastasis. For this reason, research on cancer must combine the tumor cell-intrinsic pathway with the extrinsic pathway in the tumor microenvironment. The myste- rious role of the tumor microenvironment is being deciphered in primary and metastatic tumors, particularly using various new fields such as secreted miRNAs, metabolism, and premetastasis. Targeting the tumor microenvironment combined with current clinical approaches holds great potential for developing new efficient therapies. Cancer medicine must move toward a new era of personalized diagnostics and therapeutics that aggressively embraces integrative approaches.

\section{Acknowledgements}

This study was supported by grants from the National Natural Science Foundations of China (nos. 81321002, 81502351), ISTCPC (2012DFA31370).

\section{References}

1. Hanahan D and Weinberg RA: The hallmarks of cancer. Cell 100: 57-70, 2000.

2. Hanahan D and Weinberg RA: Hallmarks of cancer: The next generation. Cell 144: 646-674, 2011.

3. Hanahan D and Coussens LM: Accessories to the crime: Functions of cells recruited to the tumor microenvironment. Cancer Cell 21: 309-322, 2012.

4. Cirri P and Chiarugi P: Cancer associated fibroblasts: The dark side of the coin. Am J Cancer Res 1: 482-497, 2011.

5. Gabrilovich DI, Ostrand-Rosenberg S and Bronte V: Coordinated regulation of myeloid cells by tumours. Nat Rev Immunol 12: 253-268, 2012.

6. Cheng L, Huang Z, Zhou W, Wu Q, Donnola S, Liu JK, Fang X, Sloan AE, Mao Y, Lathia JD, et al: Glioblastoma stem cells generate vascular pericytes to support vessel function and tumor growth. Cell 153: 139-152, 2013.

7. Cornil I, Theodorescu D, Man S, Herlyn M, Jambrosic J and Kerbel RS: Fibroblast cell interactions with human melanoma cells affect tumor cell growth as a function of tumor progression. Proc Natl Acad Sci USA 88: 6028-6032, 1991.

8. Räsänen K and Vaheri A: Activation of fibroblasts in cancer stroma. Exp Cell Res 316: 2713-2722, 2010.

9. Lu C, Vickers MF and Kerbel RS: Interleukin 6: A fibroblast-derived growth inhibitor of human melanoma cells from early but not advanced stages of tumor progression. Proc Natl Acad Sci USA 89: 9215-9219, 1992.

10. Leonardi GC, Candido S, Cervello M, Nicolosi D, Raiti F, Travali S, Spandidos DA and Libra M: The tumor microenvironment in hepatocellular carcinoma (Review). Int J Oncol 40: 1733-1747, 2012.

11. Rønnov-Jessen L and Petersen OW: Induction of alpha-smooth muscle actin by transforming growth factor-beta 1 in quiescent human breast gland fibroblasts. Implications for myofibroblast generation in breast neoplasia. Lab Invest 68: 696-707, 1993.

12. Postlethwaite AE, Keski-Oja J, Moses HL and Kang AH: Stimulation of the chemotactic migration of human fibroblasts by transforming growth factor beta. J Exp Med 165: 251-256, 1987.

13. Mayo LD, Dixon JE, Durden DL, Tonks NK and Donner DB: PTEN protects $\mathrm{p} 53$ from Mdm2 and sensitizes cancer cells to chemotherapy. J Biol Chem 277: 5484-5489, 2002.

14. Erez N, Truitt M, Olson P, Arron ST and Hanahan D: Cancer-associated fibroblasts are activated in incipient neoplasia to orchestrate tumor-promoting inflammation in an NF-kappaB-dependent manner. Cancer Cell 17: 135-147, 2010.

15. De Wever O, Demetter P, Mareel M and Bracke M: Stromal myofibroblasts are drivers of invasive cancer growth. Int J Cancer 123: 2229-2238, 2008.

16. Schmitt-Gräff A, Desmoulière A and Gabbiani G: Heterogeneity of myofibroblast phenotypic features: An example of fibroblastic cell plasticity. Virchows Arch 425: 3-24, 1994.

17. Tlsty TD and Hein PW: Know thy neighbor: Stromal cells can contribute oncogenic signals. Curr Opin Genet Dev 11: 54-59, 2001.

18. Skalli O, Pelte MF, Peclet MC, Gabbiani G, Gugliotta P, Bussolati G, Ravazzola M and Orci L: Alpha-smooth muscle actin, a differentiation marker of smooth muscle cells, is present in microfilamentous bundles of pericytes. J Histochem Cytochem 37: 315-321, 1989. 
19. De Wever O and Mareel M: Role of tissue stroma in cancer cell invasion. J Pathol 200: 429-447, 2003.

20. Pittenger MF, Mackay AM, Beck SC, Jaiswal RK, Douglas R, Mosca JD, Moorman MA, Simonetti DW, Craig S and Marshak DR: Multilineage potential of adult human mesenchymal stem cells. Science 284: 143-147, 1999.

21. Rattigan Y, Hsu JM, Mishra PJ, Glod J and Banerjee D: Interleukin 6 mediated recruitment of mesenchymal stem cells to the hypoxic tumor milieu. Exp Cell Res 316: 3417-3424, 2010.

22. Karnoub AE, Dash AB, Vo AP, Sullivan A, Brooks MW, Bell GW, Richardson AL, Polyak K, Tubo R and Weinberg RA: Mesenchymal stem cells within tumour stroma promote breast cancer metastasis. Nature 449: 557-563, 2007.

23. Zeisberg EM, Tarnavski O, Zeisberg M, Dorfman AL, McMullen JR, Gustafsson E, Chandraker A, Yuan X, Pu WT, Roberts $\mathrm{AB}$, et al: Endothelial-to-mesenchymal transition contributes to cardiac fibrosis. Nat Med 13: 952-961, 2007.

24. Zeisberg EM, Potenta S, Xie L, Zeisberg M and Kalluri R: Discovery of endothelial to mesenchymal transition as a source for carcinoma-associated fibroblasts. Cancer Res 67: 10123-10128, 2007.

25. Petersen OW, Lind Nielsen H, Gudjonsson T, Villadsen R, Rønnov-Jessen L and Bissell MJ: The plasticity of human breast carcinoma cells is more than epithelial to mesenchymal conversion. Breast Cancer Res 3: 213-217, 2001.

26. Petersen OW, Nielsen HL, Gudjonsson T, Villadsen R, Rank F, Niebuhr E, Bissell MJ and Rønnov-Jessen L: Epithelial to mesenchymal transition in human breast cancer can provide a nonmalignant stroma. Am J Pathol 162: 391-402, 2003.

27. Kurose K, Gilley K, Matsumoto S, Watson PH, Zhou XP and Eng C: Frequent somatic mutations in PTEN and TP53 are mutually exclusive in the stroma of breast carcinomas. Nat Genet 32: 355-357, 2002.

28. Orimo A and Weinberg RA: Stromal fibroblasts in cancer: A novel tumor-promoting cell type. Cell Cycle 5: 1597-1601, 2006.

29. Bronisz A, Godlewski J, Wallace JA, Merchant AS, Nowicki MO, Mathsyaraja H, Srinivasan R, Trimboli AJ, Martin CK, Li F, et al: Reprogramming of the tumour microenvironment by stromal PTEN-regulated miR-320. Nat Cell Biol 14: 159-167, 2011.

30. Sun X, Mao Y, Wang J, Zu L, Hao M, Cheng G, Qu Q, Cui D, Keller ET, Chen X, et al: IL-6 secreted by cancer-associated fibroblasts induces tamoxifen resistance in luminal breast cancer. Oncogene: Jun 9, 2014 (Epub ahead of print). doi: 10.1038/onc.2014.158

31. Sica A: Role of tumour-associated macrophages in cancerrelated inflammation. Exp Oncol 32: 153-158, 2010

32. Sica A, Larghi P, Mancino A, Rubino L, Porta C, Totaro MG, Rimoldi M, Biswas SK, Allavena P and Mantovani A: Macrophage polarization in tumour progression. Semin Cancer Biol 18: 349-355, 2008.

33. Lin EY, Nguyen AV, Russell RG and Pollard JW: Colony-stimulating factor 1 promotes progression of mammary tumors to malignancy. J Exp Med 193: 727-740, 2001.

34. Nesbit M, Schaider H, Miller TH and Herlyn M: Low-level monocyte chemoattractant protein-1 stimulation of monocytes leads to tumor formation in nontumorigenic melanoma cells. J Immunol 166: 6483-6490, 2001.

35. Schmid MC, Avraamides CJ, Dippold HC, Franco I, Foubert P, Ellies LG, Acevedo LM, Manglicmot JR, Song X, Wrasidlo W, et al: Receptor tyrosine kinases and TLR/IL1Rs unexpectedly activate myeloid cell PI $3 \mathrm{k} \gamma$, a single convergent point promoting tumor inflammation and progression. Cancer Cell 19: 715-727, 2011.

36. Balkwill F: Cancer and the chemokine network. Nat Rev Cancer 4: 540-550, 2004

37. Qian BZ, Li J, Zhang H, Kitamura T, Zhang J, Campion LR, Kaiser EA, Snyder LA and Pollard JW: CCL2 recruits inflammatory monocytes to facilitate breast-tumour metastasis. Nature 475: 222-225, 2011

38. Mizutani K, Sud S, McGregor NA, Martinovski G, Rice BT, Craig MJ, Varsos ZS, Roca H and Pienta KJ: The chemokine CCL2 increases prostate tumor growth and bone metastasis through macrophage and osteoclast recruitment. Neoplasia 11: 1235-1242, 2009.

39. Acharyya S, Oskarsson T, Vanharanta S, Malladi S, Kim J, Morris PG, Manova-Todorova K, Leversha M, Hogg N, Seshan VE, et al: A CXCL1 paracrine network links cancer chemoresistance and metastasis. Cell 150: 165-178, 2012.
40. Shields JD, Kourtis IC, Tomei AA, Roberts JM and Swartz MA: Induction of lymphoidlike stroma and immune escape by tumors that express the chemokine CCL21. Science 328: 749-752, 2010.

41. Cremer I, Fridman WH and Sautès-Fridman C: Tumor microenvironment in NSCLC suppresses NK cells function. OncoImmunology 1: 244-246, 2012.

42. Zhao X, Rong L, Zhao X, Li X, Liu X, Deng J, Wu H, Xu X, Erben U, Wu P, et al: TNF signaling drives myeloid-derived suppressor cell accumulation. J Clin Invest 122: 4094-4104, 2012.

43. Bayne LJ, Beatty GL, Jhala N, Clark CE, Rhim AD, Stanger BZ and Vonderheide RH: Tumor-derived granulocyte-macrophage colony-stimulating factor regulates myeloid inflammation and $\mathrm{T}$ cell immunity in pancreatic cancer. Cancer Cell 21: 822-835, 2012.

44. Würth R, Bajetto A, Harrison JK, Barbieri F and Florio T: CXCL12 modulation of CXCR4 and CXCR7 activity in human glioblastoma stem-like cells and regulation of the tumor microenvironment. Front Cell Neurosci 8: 144, 2014.

45. Bergers $\mathrm{G}$ and Benjamin LE: Tumorigenesis and the angiogenic switch. Nat Rev Cancer 3: 401-410, 2003.

46. Bertolini F, Shaked Y, Mancuso P and Kerbel RS: The multifaceted circulating endothelial cell in cancer: Towards marker and target identification. Nat Rev Cancer 6: 835-845, 2006.

47. Volm M, Koomägi R and Mattern J: Prognostic value of vascular endothelial growth factor and its receptor Flt-1 in squamous cell lung cancer. Int J Cancer 74: 64-68, 1997.

48. Yoshiji H, Gomez DE, Shibuya $M$ and Thorgeirsson UP: Expression of vascular endothelial growth factor, its receptor, and other angiogenic factors in human breast cancer. Cancer Res 56: 2013-2016, 1996.

49. Olson TA, Mohanraj D, Carson LF and Ramakrishnan S: Vascular permeability factor gene expression in normal and neoplastic human ovaries. Cancer Res 54: 276-280, 1994.

50. Brown LF, Berse B, Jackman RW, Tognazzi K, Manseau EJ, Dvorak HF and Senger DR: Increased expression of vascular permeability factor (vascular endothelial growth factor) and its receptors in kidney and bladder carcinomas. Am J Pathol 143: 1255-1262, 1993

51. Asahara T, Takahashi T, Masuda H, Kalka C, Chen D, Iwaguro H, Inai $\mathrm{Y}$, Silver M and Isner JM: VEGF contributes to postnatal neovascularization by mobilizing bone marrow-derived endothelial progenitor cells. EMBO J 18: 3964-3972, 1999.

52. Png KJ, Halberg N, Yoshida M and Tavazoie SF: A microRNA regulon that mediates endothelial recruitment and metastasis by cancer cells. Nature 481: 190-194, 2011.

53. Zeng Z, Li YC, Jiao ZH, Yao J and Xue Y: The cross talk between cGMP signal pathway and PKC in pulmonary endothelial cell angiogenesis. Int J Mol Sci 15: 10185-10198, 2014.

54. Karar J and Maity A: PI3K/AKT/mTOR pathway in angiogenesis. Front Mol Neurosci 4: 51, 2011

55. Wang Z, Martin D, Molinolo AA, Patel V, Iglesias-Bartolome R, Degese MS, Vitale-Cross L, Chen Q and Gutkind JS: mTOR co-targeting in cetuximab resistance in head and neck cancers harboring PIK3CA and RAS mutations. J Natl Cancer Inst 106: dju215, 2014

56. Patel V, Marsh CA, Dorsam RT, Mikelis CM, Masedunskas A, Amornphimoltham P, Nathan CA, Singh B, Weigert R, Molinolo AA, et al: Decreased lymphangiogenesis and lymph node metastasis by mTOR inhibition in head and neck cancer Cancer Res 71: 7103-7112, 2011.

57. Oft $\mathrm{M}$, Heider $\mathrm{KH}$ and Beug $\mathrm{H}$ : TGFbeta signaling is necessary for carcinoma cell invasiveness and metastasis. Curr Biol 8: 1243-1252, 1998

58. Biswas S, Guix M, Rinehart C, Dugger TC, Chytil A, Moses HL, Freeman ML and Arteaga CL: Inhibition of TGF-beta with neutralizing antibodies prevents radiation-induced acceleration of metastatic cancer progression. J Clin Invest 117: 1305-1313, 2007.

59. Padua D, Zhang XH, Wang Q, Nadal C, Gerald WL, Gomis RR and Massagué J: TGFbeta primes breast tumors for lung metastasis seeding through angiopoietin-like 4. Cell 133: 66-77, 2008.

60. Siegel PM, Shu W, Cardiff RD, Muller WJ and Massagué J: Transforming growth factor beta signaling impairs Neu-induced mammary tumorigenesis while promoting pulmonary metastasis. Proc Natl Acad Sci USA 100: 8430-8435, 2003.

61. Yin JJ, Selander K, Chirgwin JM, Dallas M, Grubbs BG, Wieser R, Massagué J, Mundy GR and Guise TA: TGF-beta signaling blockade inhibits PTHrP secretion by breast cancer cells and bone metastases development. J Clin Invest 103: 197-206, 1999. 
62. Kang Y, He W, Tulley S, Gupta GP, Serganova I, Chen CR, Manova-Todorova K, Blasberg R, Gerald WL and Massagué J: Breast cancer bone metastasis mediated by the Smad tumor suppressor pathway. Proc Natl Acad Sci USA 102: 13909-13914, 2005.

63. Labelle M, Begum S and Hynes RO: Direct signaling between platelets and cancer cells induces an epithelial-mesenchymal-like transition and promotes metastasis. Cancer Cell 20: 576-590, 2011.

64. Nakamura T, Nishizawa T, Hagiya M, Seki T, Shimonishi M, Sugimura A, Tashiro K and Shimizu S: Molecular cloning and expression of human hepatocyte growth factor. Nature 342 440-443, 1989.

65. Birchmeier C, Birchmeier W, Gherardi E and Vande Woude GF Met, metastasis, motility and more. Nat Rev Mol Cell Biol 4 915-925, 2003

66. Matsumoto K and Nakamura T: Hepatocyte growth factor and the Met system as a mediator of tumor-stromal interactions. Int J Cancer 119: 477-483, 2006.

67. Wilson TR, Fridlyand J, Yan Y, Penuel E, Burton L, Chan E, Peng J, Lin E, Wang Y, Sosman J, et al: Widespread potential for growth-factor-driven resistance to anticancer kinase inhibitors. Nature 487: 505-509, 2012

68. Straussman R, Morikawa T, Shee K, Barzily-Rokni M, Qian ZR Du J, Davis A, Mongare MM, Gould J, Frederick DT, et al: Tumour micro-environment elicits innate resistance to RAF inhibitors through HGF secretion. Nature 487: 500-504, 2012.

69. Zhou P, Li H, Wheeler S, Grandis JR, Stabile LA and Egloff AM: Generation of head and neck cancer patient-derived xenografts with in vivo acquired cetuximab resistance. Clin Cancer Res 21 (Suppl 4): B39, 2015.

70. Rossi D and Zlotnik A: The biology of chemokines and their receptors. Annu Rev Immunol 18: 217-242, 2000.

71. Murphy PM, Baggiolini M, Charo IF, Hébert CA, Horuk R, Matsushima K, Miller LH, Oppenheim JJ and Power CA: International union of pharmacology. XXII. Nomenclature for chemokine receptors. Pharmacol Rev 52: 145-176, 2000.

72. Zlotnik A and Yoshie O: Chemokines: A new classification system and their role in immunity. Immunity 12: 121-127, 2000.

73. Dhawan P and Richmond A: Role of CXCL1 in tumorigenesis of melanoma. J Leukoc Biol 72: 9-18, 2002.

74. Wang D, Wang H, Brown J, Daikoku T, Ning W, Shi Q, Richmond A, Strieter R, Dey SK and DuBois RN: CXCL1 induced by prostaglandin $\mathrm{E} 2$ promotes angiogenesis in colorectal cancer. J Exp Med 203: 941-951, 2006.

75. Karunagaran D, Tzahar E, Beerli RR, Chen X, Graus-Porta D, Ratzkin BJ, Seger R, Hynes NE and Yarden Y: ErbB-2 is a common auxiliary subunit of NDF and EGF receptors: Implications for breast cancer. EMBO J 15: 254-264, 1996.

76. Conti I and Rollins BJ: CCL2 (monocyte chemoattractant protein-1) and cancer. Semin Cancer Biol 14: 149-154, 2004.

77. Craig MJ and Loberg RD: CCL2 (monocyte chemoattractant protein-1) in cancer bone metastases. Cancer Metastasis Rev 25 611-619, 2006

78. Popivanova BK, Kostadinova FI, Furuichi K, Shamekh MM, Kondo T, Wada T, Egashira K and Mukaida N: Blockade of a chemokine, CCL2, reduces chronic colitis-associated carcinogenesis in mice. Cancer Res 69: 7884-7892, 2009.

79. Rottiers V and Näär AM: MicroRNAs in metabolism and metabolic disorders. Nat Rev Mol Cell Biol 13: 239-250, 2012.

80. Krützfeldt J and Stoffel M: MicroRNAs: A new class of regulatory genes affecting metabolism. Cell Metab 4: 9-12, 2006

81. Calin GA and Croce CM: MicroRNA signatures in human cancers. Nat Rev Cancer 6: 857-866, 2006.

82. Kosaka N, Iguchi H, Yoshioka Y, Takeshita F, Matsuki Y and Ochiya T: Secretory mechanisms and intercellular transfer of microRNAs in living cells. J Biol Chem 285: 17442-17452, 2010

83. Zhang J, Zhao H, Gao Y and Zhang W: Secretory miRNAs as novel cancer biomarkers. Biochim Biophys Acta 1826: 32-43, 2012.

84. Xu D and Tahara H: The role of exosomes and microRNAs in senescence and aging. Adv Drug Deliv Rev 65: 368-375, 2013.

85. Kosaka N, Iguchi H, Yoshioka Y, Hagiwara K, Takeshita F and Ochiya T: Competitive interactions of cancer cells and normal cells via secretory microRNAs. J Biol Chem 287: 1397-1405, 2012.

86. Yang M, Chen J, Su F, Yu B, Su F, Lin L, Liu Y, Huang JD and Song E: Microvesicles secreted by macrophages shuttle invasion-potentiating microRNAs into breast cancer cells. Mol Cancer 10: 117, 2011.
87. Fabbri M, Paone A, Calore F, Galli R, Gaudio E, Santhanam R, Lovat F, Fadda P, Mao C, Nuovo GJ, et al: MicroRNAs bind to Toll-like receptors to induce prometastatic inflammatory response. Proc Natl Acad Sci USA 109: E2110-E2116, 2012.

88. Roth C, Rack B, Müller V, Janni W, Pantel K and Schwarzenbach H: Circulating microRNAs as blood-based markers for patients with primary and metastatic breast cancer. Breast Cancer Res 12: R90, 2010.

89. Mitchell PS, Parkin RK, Kroh EM, Fritz BR, Wyman SK, Pogosova-Agadjanyan EL, Peterson A, Noteboom J, O'Briant KC, Allen A, et al: Circulating microRNAs as stable blood-based markers for cancer detection. Proc Natl Acad Sci USA 105: 10513-10518, 2008.

90. Cairns RA, Harris IS and Mak TW: Regulation of cancer cell metabolism. Nat Rev Cancer 11: 85-95, 2011

91. Vander Heiden MG, Cantley LC and Thompson CB: Understanding the Warburg effect: The metabolic requirements of cell proliferation. Science 324: 1029-1033, 2009.

92. Lunt SY and Vander Heiden MG: Aerobic glycolysis: Meeting the metabolic requirements of cell proliferation. Annu Rev Cell Dev Biol 27: 441-464, 2011.

93. Riemann A, Schneider B, Ihling A, Nowak M, Sauvant C Thews $\mathrm{O}$ and Gekle M: Acidic environment leads to ROS-induced MAPK signaling in cancer cells. PLoS One 6: e22445, 2011.

94. Fischer K, Hoffmann P, Voelkl S, Meidenbauer N, Ammer J, Edinger M, Gottfried E, Schwarz S, Rothe G, Hoves S, et al: Inhibitory effect of tumor cell-derived lactic acid on human T cells. Blood 109: 3812-3819, 2007.

95. Walenta S and Mueller-Klieser WF: Lactate: Mirror and motor of tumor malignancy. Semin Radiat Oncol 14: 267-274, 2004.

96. Rattigan YI, Patel BB, Ackerstaff E, Sukenick G, Koutcher JA, Glod JW and Banerjee D: Lactate is a mediator of metabolic cooperation between stromal carcinoma associated fibroblasts and glycolytic tumor cells in the tumor microenvironment. Exp Cell Res 318: 326-335, 2012.

97. Végran F, Boidot R, Michiels C, Sonveaux P and Feron O Lactate influx through the endothelial cell monocarboxylate transporter MCT1 supports an NF- $\mathrm{KB} / \mathrm{IL}-8$ pathway that drives tumor angiogenesis. Cancer Res 71: 2550-2560, 2011.

98. Semenza GL: Tumor metabolism: Cancer cells give and take lactate. J Clin Invest 118: 3835-3837, 2008.

99. Feron O: Pyruvate into lactate and back: From the Warburg effect to symbiotic energy fuel exchange in cancer cells. Radiother Oncol 92: 329-333, 2009.

100. Sonveaux P, Végran F, Schroeder T, Wergin MC, Verrax J, Rabbani ZN, De Saedeleer CJ, Kennedy KM, Diepart C, Jordan BF, et al: Targeting lactate-fueled respiration selectively kills hypoxic tumor cells in mice. J Clin Invest 118: 3930-3942, 2008.

101. Koukourakis MI, Giatromanolaki A, Harris AL and Sivridis E: Comparison of metabolic pathways between cancer cells and stromal cells in colorectal carcinomas: A metabolic survival role for tumor-associated stroma. Cancer Res 66: 632-637, 2006

102. Nieman KM, Kenny HA, Penicka CV, Ladanyi A, BuellGutbrod R, Zillhardt MR, Romero IL, Carey MS, Mills GB, Hotamisligil GS, et al: Adipocytes promote ovarian cancer metastasis and provide energy for rapid tumor growth. Nat Med 17: 1498-1503, 2011

103. Marie SK and Shinjo SM: Metabolism and brain cancer. Clinics (Sao Paulo) 66 (Suppl 1): 33-43, 2011.

104. Hirayama A, Kami K, Sugimoto M, Sugawara M, Toki N, Onozuka H, Kinoshita T, Saito N, Ochiai A, Tomita M, et al: Quantitative metabolome profiling of colon and stomach cancer microenvironment by capillary electrophoresis time-of-flight mass spectrometry. Cancer Res 69: 4918-4925, 2009.

105. Ko YH, Lin Z, Flomenberg N, Pestell RG, Howell A, Sotgia F, Lisanti MP and Martinez-Outschoorn UE: Glutamine fuels a vicious cycle of autophagy in the tumor stroma and oxidative mitochondrial metabolism in epithelial cancer cells: Implications for preventing chemotherapy resistance. Cancer Biol Ther 12: 1085-1097, 2011.

106. Filipp FV, Ratnikov B, De Ingeniis J, Smith JW, Osterman AL and Scott DA: Glutamine-fueled mitochondrial metabolism is decoupled from glycolysis in melanoma. Pigment Cell Melanoma Res 25: 732-739, 2012.

107. Jain M, Nilsson R, Sharma S, Madhusudhan N, Kitami T, Souza AL, Kafri R, Kirschner MW, Clish CB and Mootha VK: Metabolite profiling identifies a key role for glycine in rapid cancer cell proliferation. Science 336: 1040-1044, 2012. 
108. Okamoto K, Toyokuni S, Kim WJ, Ogawa O, Kakehi Y, Arao S, Hiai $\mathrm{H}$ and Yoshida O: Overexpression of human mut $\mathrm{T}$ homologue gene messenger RNA in renal-cell carcinoma: evidence of persistent oxidative stress in cancer. Int J Cancer 65: 437-441, 1996.

109. Gackowski D, Banaszkiewicz Z, Rozalski R, Jawien A and Olinski R: Persistent oxidative stress in colorectal carcinoma patients. Int J Cancer 101: 395-397, 2002.

110. Toyokuni S, Okamoto K, Yodoi J and Hiai H: Persistent ox idative stress in cancer. FEBS Lett 358: 1-3, 1995.

111. Zhou Y, Hileman EO, Plunkett W, Keating MJ and Huang P: Free radical stress in chronic lymphocytic leukemia cells and its role in cellular sensitivity to ROS-generating anticancer agents. Blood 101: 4098-4104, 2003.

112. Szatrowski TP and Nathan CF: Production of large amounts of hydrogen peroxide by human tumor cells. Cancer Res 51: 794-798, 1991.

113. Grivennikov SI, Greten FR and Karin M: Immunity, inflammation, and cancer. Cell 140: 883-899, 2010

114. Ishikawa K, Takenaga K, Akimoto M, Koshikawa N, Yamaguchi A, Imanishi H, Nakada K, Honma Y and Hayashi J: ROS-generating mitochondrial DNA mutations can regulate tumor cell metastasis. Science 320: 661-664, 2008.

115. Trachootham D, Alexandre J and Huang P: Targeting cancer cells by ROS-mediated mechanisms: A radical therapeutic approach? Nat Rev Drug Discov 8: 579-591, 2009.

116. Martinez-Outschoorn UE, Lin Z, Trimmer C, Flomenberg N, Wang C, Pavlides S, Pestell RG, Howell A, Sotgia F and Lisanti MP: Cancer cells metabolically 'fertilize' the tumor microenvironment with hydrogen peroxide, driving the Warburg effect: Implications for PET imaging of human tumors. Cell Cycle 10: 2504-2520, 2011.

117. Mathew R, Karantza-Wadsworth V and White E: Role of autophagy in cancer. Nat Rev Cancer 7: 961-967, 2007.

118. Baehrecke EH: Autophagy: Dual roles in life and death? Nat Rev Mol Cell Biol 6: 505-510, 2005.

119. Eisenberg-Lerner A and Kimchi A: The paradox of autophagy and its implication in cancer etiology and therapy. Apoptosis 14 376-391, 2009.

120.Pavlides S, Tsirigos A, Migneco G, Whitaker-Menezes D, Chiavarina B, Flomenberg N, Frank PG, Casimiro MC, Wang C, Pestell RG, et al: The autophagic tumor stroma model of cancer: Role of oxidative stress and ketone production in fueling tumor cell metabolism. Cell Cycle 9: 3485-3505, 2010.

121. Martinez-Outschoorn UE, Balliet RM, Rivadeneira DB, Chiavarina B, Pavlides S, Wang C, Whitaker-Menezes D, Daumer KM, Lin Z, Witkiewicz AK, et al: Oxidative stress in cancer associated fibroblasts drives tumor-stroma co-evolution: A new paradigm for understanding tumor metabolism, the field effect and genomic instability in cancer cells. Cell Cycle 9: 3256-3276, 2010.

122. Bonuccelli G, Tsirigos A, Whitaker-Menezes D, Pavlides S, Pestell RG, Chiavarina B, Frank PG, Flomenberg N, Howell A, Martinez-Outschoorn UE, et al: Ketones and lactate 'fuel' tumor growth and metastasis: Evidence that epithelial cancer cells use oxidative mitochondrial metabolism. Cell Cycle 9: 3506-3514, 2010.

123. Martinez-Outschoorn UE, Trimmer C, Lin Z, Whitaker-Menezes D, Chiavarina B, Zhou J, Wang C, Pavlides S, Martinez-Cantarin MP, Capozza F, et al: Autophagy in cancer associated fibroblasts promotes tumor cell survival: Role of hypoxia, HIF1 induction and $\mathrm{NF \kappa B}$ activation in the tumor stromal microenvironment. Cell Cycle 9: 3515-3533, 2010.

124. Chiavarina B, Whitaker-Menezes D, Migneco G, MartinezOutschoorn UE, Pavlides S, Howell A, Tanowitz HB, Casimiro MC, Wang C, Pestell RG, et al: HIF1-alpha functions as a tumor promoter in cancer associated fibroblasts, and as a tumor suppressor in breast cancer cells: Autophagy drives compartmentspecific oncogenesis. Cell Cycle 9: 3534-3551, 2010.

125. Martinez-Outschoorn UE, Whitaker-Menezes D, Pavlides S, Chiavarina B, Bonuccelli G, Casey T, Tsirigos A, Migneco G, Witkiewicz A, Balliet R, et al: The autophagic tumor stroma model of cancer or 'battery-operated tumor growth': A simple solution to the autophagy paradox. Cell Cycle 9: 4297-4306, 2010.

126. Salem AF, Whitaker-Menezes D, Lin Z, MartinezOutschoorn UE, Tanowitz HB, Al-Zoubi MS, Howell A, Pestell RG, Sotgia F and Lisanti MP: Two-compartment tumor metabolism: Autophagy in the tumor microenvironment and oxidative mitochondrial metabolism (OXPHOS) in cancer cells. Cell Cycle 11: 2545-2556, 2012.
127.Zhang W, Trachootham D, Liu J, Chen G, Pelicano H, Garcia-Prieto C, Lu W, Burger JA, Croce CM, Plunkett W, et al: Stromal control of cystine metabolism promotes cancer cell survival in chronic lymphocytic leukaemia. Nat Cell Biol 14: 276-286, 2012

128. Carmeliet $P$ and Jain RK: Molecular mechanisms and clinical applications of angiogenesis. Nature 473: 298-307, 2011.

129. Risau W: Mechanisms of angiogenesis. Nature 386: 671-674, 1997.

130. Carmeliet P and Jain RK: Angiogenesis in cancer and other diseases. Nature 407: 249-257, 2000.

131. Leek RD, Lewis CE, Whitehouse R, Greenall M, Clarke J and Harris AL: Association of macrophage infiltration with angiogenesis and prognosis in invasive breast carcinoma. Cancer Res 56: 4625-4629, 1996.

132. Polverini PJ and Leibovich SJ: Induction of neovascularization in vivo and endothelial proliferation in vitro by tumor-associated macrophages. Lab Invest 51: 635-642, 1984.

133. O'Sullivan C, Lewis CE, Harris AL and McGee JO: Secretion of epidermal growth factor by macrophages associated with breast carcinoma. Lancet 342: 148-149, 1993.

134. Lewis CE, Leek R, Harris A and McGee JO: Cytokine regulation of angiogenesis in breast cancer: The role of tumor-associated macrophages. J Leukoc Biol 57: 747-751, 1995.

135. Harmey JH, Dimitriadis E, Kay E, Redmond HP and Bouchier-Hayes D: Regulation of macrophage production of vascular endothelial growth factor (VEGF) by hypoxia and transforming growth factor beta-1. Ann Surg Oncol 5: 271-278, 1998.

136. Stockmann C, Doedens A, Weidemann A, Zhang N, Takeda N, Greenberg JI, Cheresh DA and Johnson RS: Deletion of vascular endothelial growth factor in myeloid cells accelerates tumorigenesis. Nature 456: 814-818, 2008.

137. Bingle L, Lewis CE, Corke KP, Reed MW and Brown NJ: Macrophages promote angiogenesis in human breast tumour spheroids in vivo. Br J Cancer 94: 101-107, 2006.

138. Voronov E, Shouval DS, Krelin Y, Cagnano E, Benharroch D, Iwakura Y, Dinarello CA and Apte RN: IL-1 is required for tumor invasiveness and angiogenesis. Proc Natl Acad Sci USA 100: 2645-2650, 2003.

139. Chen P, Huang Y, Bong R, Ding Y, Song N, Wang X, Song X and Luo Y: Tumor-associated macrophages promote angiogenesis and melanoma growth via adrenomedullin in a paracrine and autocrine manner. Clin Cancer Res 17: 7230-7239, 2011.

140. Mazzieri R, Pucci F, Moi D, Zonari E, Ranghetti A, Berti A, Politi LS, Gentner B, Brown JL, Naldini L, et al: Targeting the ANG2/TIE2 axis inhibits tumor growth and metastasis by impairing angiogenesis and disabling rebounds of proangiogenic myeloid cells. Cancer Cell 19: 512-526, 2011.

141. Hughes R, Fang HY, Muthana M and Lewis CE: Role of tumour-associated macrophages in the regulation of angiogenesis. Tumour-Associated Macrophages: 17-29, 2011.

142. Giraudo E, Inoue M and Hanahan D: An amino-bisphosphonate targets MMP-9-expressing macrophages and angiogenesis to impair cervical carcinogenesis. J Clin Invest 114: 623-633, 2004.

143. Li ZR, Li YP, Lin ML, Su WR, Zhang WX, Zhang Y, Yao L and Liang D: Activated macrophages induce neovascularization through upregulation of MMP-9 and VEGF in rat corneas. Cornea 31: 1028-1035, 2012.

144. Houghton AM, Grisolano JL, Baumann ML, Kobayashi DK, Hautamaki RD, Nehring LC, Cornelius LA and Shapiro SD: Macrophage elastase (matrix metalloproteinase-12) suppresses growth of lung metastases. Cancer Res 66: 6149-6155, 2006.

145. Guo X, Oshima H, Kitmura T, Taketo MM and Oshima M: Stromal fibroblasts activated by tumor cells promote angiogenesis in mouse gastric cancer. J Biol Chem 283: 19864-19871, 2008.

146.Zhang Y, Tang H, Cai J, Zhang T, Guo J, Feng D and Wang Z: Ovarian cancer-associated fibroblasts contribute to epithelial ovarian carcinoma metastasis by promoting angiogenesis, lymphangiogenesis and tumor cell invasion. Cancer Lett 303: 47-55, 2011.

147. Friedl P and Wolf K: Tumour-cell invasion and migration: Diversity and escape mechanisms. Nat Rev Cancer 3: 362-374, 2003.

148. Steeg PS: Tumor metastasis: Mechanistic insights and clinical challenges. Nat Med 12: 895-904, 2006.

149. Valastyan S and Weinberg RA: Tumor metastasis: Molecular insights and evolving paradigms. Cell 147: 275-292, 2011.

150.Liotta LA, Kleinerman J, Catanzaro P and Rynbrandt D: Degradation of basement membrane by murine tumor cells. $J$ Natl Cancer Inst 58: 1427-1431, 1977. 
151. Liotta LA: Tumor invasion and metastases - role of the extracellular matrix: Rhoads Memorial Award lecture. Cancer Res 46: 1-7, 1986.

152. Fingleton B, Vargo-Gogola T, Crawford HC and Matrisian LM: Matrilysin [MMP-7] expression selects for cells with reduced sensitivity to apoptosis. Neoplasia 3: 459-468, 2001.

153. Noë V, Fingleton B, Jacobs K, Crawford HC, Vermeulen S, Steelant W, Bruyneel E, Matrisian LM and Mareel M: Release of an invasion promoter E-cadherin fragment by matrilysin and stromelysin-1. J Cell Sci 114: 111-118, 2001.

154. Sameni M, Dosescu J, Moin K and Sloane BF: Functional imaging of proteolysis: Stromal and inflammatory cells increase tumor proteolysis. Mol Imaging 2: 159-175, 2003.

155. Grimshaw MJ, Hagemann T, Ayhan A, Gillett CE, Binder C and Balkwill FR: A role for endothelin-2 and its receptors in breast tumor cell invasion. Cancer Res 64: 2461-2468, 2004.

156. Sahai E: Mechanisms of cancer cell invasion. Curr Opin Genet Dev 15: 87-96, 2005.

157. Gaggioli C, Hooper S, Hidalgo-Carcedo C, Grosse R, Marshall JF, Harrington K and Sahai E: Fibroblast-led collective invasion of carcinoma cells with differing roles for RhoGTPases in leading and following cells. Nat Cell Biol 9: 1392-1400, 2007.

158. Provenzano PP, Eliceiri KW, Campbell JM, Inman DR, White JG and Keely PJ: Collagen reorganization at the tumor-stromal interface facilitates local invasion. BMC Med 4: 38, 2006

159. Provenzano PP, Inman DR, Eliceiri KW, Trier SM and Keely PJ: Contact guidance mediated three-dimensional cell migration is regulated by $\mathrm{Rho} / \mathrm{ROCK}$-dependent matrix reorganization. Biophys J 95: 5374-5384, 2008.

160. Goetz JG, Minguet S, Navarro-Lérida I, Lazcano JJ, Samaniego R, Calvo E, Tello M, Osteso-Ibáñez T, Pellinen T, Echarri A, et al: Biomechanical remodeling of the microenvironment by stromal caveolin-1 favors tumor invasion and metastasis. Cell 146: 148-163, 2011.

161. Chen J, Yao Y, Gong C, Yu F, Su S, Chen J, Liu B, Deng H, Wang F, Lin L, et al: CCL18 from tumor-associated macrophages promotes breast cancer metastasis via PITPNM3. Cancer Cell 19: 541-555, 2011.

162. Yamaguchi H, Pixley F and Condeelis J: Invadopodia and podosomes in tumor invasion. Eur J Cell Biol 85: 213-218, 2006.

163. Yamaguchi H, Lorenz M, Kempiak S, Sarmiento C, Coniglio S, Symons M, Segall J, Eddy R, Miki H, Takenawa T, et al: Molecular mechanisms of invadopodium formation: The role of the N-WASP-Arp2/3 complex pathway and cofilin. J Cell Biol 168 441-452, 2005

164. Buccione R, Orth JD and McNiven MA: Foot and mouth: Podosomes, invadopodia and circular dorsal ruffles. Nat Rev Mol Cell Biol 5: 647-657, 2004.

165. Calle Y, Chou HC, Thrasher AJ and Jones GE: Wiskott-Aldrich syndrome protein and the cytoskeletal dynamics of dendritic cells. J Pathol 204: 460-469, 2004.

166. Linder S and Aepfelbacher M: Podosomes: Adhesion hot-spots of invasive cells. Trends Cell Biol 13: 376-385, 2003.

167. Mizutani K, Miki H, He H, Maruta H and Takenawa T: Essential role of neural Wiskott-Aldrich syndrome protein in podosome formation and degradation of extracellular matrix in src-transformed fibroblasts. Cancer Res 62: 669-674, 2002.

168. Moreno-Bueno G, Portillo F and Cano A: Transcriptional regulation of cell polarity in EMT and cancer. Oncogene 27: 6958-6969, 2008 .

169. Thiery JP: Epithelial-mesenchymal transitions in tumour progression. Nat Rev Cancer 2: 442-454, 2002.

170. Liu R, Li J, Xie K, Zhang T, Lei Y, Chen Y, Zhang L, Huang K, Wang K, Wu H, et al: FGFR4 promotes stroma-induced epithelialto-mesenchymal transition in colorectal cancer. Cancer Res 73 5926-5935, 2013.

171. Bergers G, Song S, Meyer-Morse N, Bergsland E and Hanahan D: Benefits of targeting both pericytes and endothelial cells in the tumor vasculature with kinase inhibitors. J Clin Invest 111: 1287$1295,2003$.

172. Raza A, Franklin MJ and Dudek AZ: Pericytes and vessel maturation during tumor angiogenesis and metastasis. Am J Hematol 85 593-598, 2010.

173. Cooke VG, LeBleu VS, Keskin D, Khan Z, O'Connell JT, Teng Y, Duncan MB, Xie L, Maeda G, Vong S, et al: Pericyte depletion results in hypoxia-associated epithelial-to-mesenchymal transition and metastasis mediated by met signaling pathway. Cancer Cell 21: 66-81, 2012

174. Cano A, Pérez-Moreno MA, Rodrigo I, Locascio A, Blanco MJ, del Barrio MG, Portillo F and Nieto MA: The transcription factor snail controls epithelial-mesenchymal transitions by repressing E-cadherin expression. Nat Cell Biol 2: 76-83, 2000.
175.Batlle E, Sancho E, Francí C, Domínguez D, Monfar M, Baulida J and García De Herreros A: The transcription factor snail is a repressor of E-cadherin gene expression in epithelial tumour cells. Nat Cell Biol 2: 84-89, 2000.

176.Zhou BP, Deng J, Xia W, Xu J, Li YM, Gunduz M and Hung MC: Dual regulation of Snail by GSK-3beta-mediated phosphorylation in control of epithelial-mesenchymal transition. Nat Cell Biol 6: 931-940, 2004.

177.Wu Y, Deng J, Rychahou PG, Qiu S, Evers BM and Zhou BP: Stabilization of snail by NF-kappaB is required for inflammation-induced cell migration and invasion. Cancer Cell 15: 416-428, 2009.

178.Quigley JP and Armstrong PB: Tumor cell intravasation alu-cidated: The chick embryo opens the window. Cell 94: 281-284, 1998

179. Wyckoff JB, Jones JG, Condeelis JS and Segall JE: A critical step in metastasis: In vivo analysis of intravasation at the primary tumor. Cancer Res 60: 2504-2511, 2000.

180. Wolf MJ, Hoos A, Bauer J, Boettcher S, Knust M, Weber A, Simonavicius N, Schneider C, Lang M, Stürzl M, et al: Endothelial CCR2 signaling induced by colon carcinoma cells enables extravasation via the JAK2-Stat5 and p38MAPK pathway. Cancer Cell 22: 91-105, 2012

181. Gay LJ and Felding-Habermann B: Contribution of platelets to tumour metastasis. Nat Rev Cancer 11: 123-134, 2011.

182. Nagrath S, Sequist LV, Maheswaran S, Bell DW, Irimia D, Ulkus L, Smith MR, Kwak EL, Digumarthy S, Muzikansky $\mathrm{A}$, et al: Isolation of rare circulating tumour cells in cancer patients by microchip technology. Nature 450: 1235-1239, 2007.

183.Huang YY, Hoshino $\mathrm{K}$, Chen $\mathrm{P}, \mathrm{Wu} \mathrm{CH}$, Lane $\mathrm{N}$, Huebschman M, Liu H, Sokolov K, Uhr JW, Frenkel EP, et al: Immunomagnetic nanoscreening of circulating tumor cells with a motion controlled microfluidic system. Biomed Microdevices 15: 673-681, 2013.

184. Cai $\mathrm{H}$ and Peng F: 2-NBDG fluorescence imaging of hypermetabolic circulating tumor cells in mouse xenograft model of breast cancer. J Fluoresc 23: 213-220, 2013.

185. Nieswandt B, Hafner M, Echtenacher B and Männel DN: Lysis of tumor cells by natural killer cells in mice is impeded by platelets. Cancer Res 59: 1295-1300, 1999.

186. Mbeunkui F and Johann DJ Jr: Cancer and the tumor microenvironment: A review of an essential relationship. Cancer Chemother Pharmacol 63: 571-582, 2009.

187. Gupta GP, Nguyen DX, Chiang AC, Bos PD, Kim JY, Nadal C, Gomis RR, Manova-Todorova K and Massagué J: Mediators of vascular remodelling co-opted for sequential steps in lung metastasis. Nature 446: 765-770, 2007.

188.Psaila B, Kaplan RN, Port ER and Lyden D: Priming the 'soil' for breast cancer metastasis: The pre-metastatic niche. Breast Dis 26: 65-74, 2006-2007.

189.Psaila B and Lyden D: The metastatic niche: Adapting the foreign soil. Nat Rev Cancer 9: 285-293, 2009.

190.Hiratsuka S, Watanabe A, Aburatani H and Maru Y: Tumourmediated upregulation of chemoattractants and recruitment of myeloid cells predetermines lung metastasis. Nat Cell Biol 8: $1369-1375,2006$

191. Rafii S and Lyden D: S100 chemokines mediate bookmarking of premetastatic niches. Nat Cell Biol 8: 1321-1323, 2006.

192. Hiratsuka S, Watanabe A, Sakurai Y, Akashi-Takamura S, Ishibashi S, Miyake K, Shibuya M, Akira S, Aburatani H and Maru Y: The S100A8-serum amyloid A3-TLR4 paracrine cascade establishes a pre-metastatic phase. Nat Cell Biol 10: 1349-1355, 2008

193. Kaplan RN, Riba RD, Zacharoulis S, Bramley AH, Vincent L, Costa C, MacDonald DD, Jin DK, Shido K, Kerns SA, et al: VEGFR1-positive haematopoietic bone marrow progenitors initiate the pre-metastatic niche. Nature 438: 820-827, 2005.

194.Nakasone ES, Askautrud HA, Kees T, Park JH, Plaks V, Ewald AJ, Fein M, Rasch MG, Tan YX, Qiu J, et al: Imaging tumor-stroma interactions during chemotherapy reveals contributions of the microenvironment to resistance. Cancer Cell 21: 488-503, 2012

195.Roodhart JM, Daenen LG, Stigter EC, Prins HJ, Gerrits J, Houthuijzen JM, Gerritsen MG, Schipper HS, Backer MJ, van Amersfoort $\mathrm{M}$, et al: Mesenchymal stem cells induce resistance to chemotherapy through the release of platinum-induced fatty acids. Cancer Cell 20: 370-383, 2011.

196.Joosse SA and Pantel K: Tumor-educated platelets as liquid biopsy in cancer patients. Cancer Cell 28: 552-554, 2015. 
197. Wong HK, Fatimy RE, Onodera C, Wei Z, Yi M, Mohan A, Gowrisankaran S, Karmali P, Marcusson E, Wakimoto H, et al: The Cancer Genome Atlas Analysis predicts microRNA for targeting cancer growth and vascularization in glioblastoma. Mol Ther 23: 1234-1247, 2015.

198. Resnick MJ, Lopatin M, Shore ND, Lam PN, Helfand B, Abramson RD, Crager M, Bonham M, Tezcan $H$ Clark-Langone KM, et al: Analysis of tumor DNA in urine as a highly sensitive liquid biopsy for patients with non-muscle invasive bladder cancer (NMIBC). Clin Cancer Res 22: 14, 2016.

199.Mishra RK, Wei C, Hresko RC, Bajpai R, Heitmeier M Matulis SM, Nooka AK, Rosen ST, Hruz PW, Schiltz GE, et al: In silico modeling-based identification of glucose transporter 4 (GLUT4)-selective inhibitors for cancer therapy. J Biol Chem 290: 14441-14453, 2015.

200. Tuxhorn JA, McAlhany SJ, Yang F, Dang TD and Rowley DR: Inhibition of transforming growth factor-beta activity decreases angiogenesis in a human prostate cancer-reactive stroma xenograft model. Cancer Res 62: 6021-6025, 2002.

201. Carmeliet P: Angiogenesis in health and disease. Nat Med 9: 653-660, 2003.

202.Joyce JA, Freeman C, Meyer-Morse N, Parish CR and Hanahan D: A functional heparan sulfate mimetic implicates both heparanase and heparan sulfate in tumor angiogenesis and invasion in a mouse model of multistage cancer. Oncogene 24 4037-4051, 2005.

203. Hamano Y, Zeisberg M, Sugimoto H, Lively JC, Maeshima Y, Yang C, Hynes RO, Werb Z, Sudhakar A and Kalluri R: Physiological levels of tumstatin, a fragment of collagen IV alpha3 chain, are generated by MMP-9 proteolysis and suppress angiogenesis via alphaV beta3 integrin. Cancer Cell 3: 589-601, 2003.

204. Rudland PS, Platt-Higgins A, El-Tanani M, De Silva Rudland S, Barraclough R, Winstanley JH, Howitt R and West CR: Prognostic significance of the metastasis-associated protein osteopontin in human breast cancer. Cancer Res 62: 3417-3427, 2002.

205.El-Tanani MK, Campbell FC, Kurisetty V, Jin D, McCann M and Rudland PS: The regulation and role of osteopontin in malignant transformation and cancer. Cytokine Growth Factor Rev 17: 463-474, 2006.

206. Tuck AB and Chambers AF: The role of osteopontin in breast cancer: Clinical and experimental studies. J Mammary Gland Biol Neoplasia 6: 419-429, 2001.

207. Weber GF: The metastasis gene osteopontin: A candidate target for cancer therapy. Biochim Biophys Acta 1552: 61-85, 2001

208. Matarrese P, Fusco O, Tinari N, Natoli C, Liu FT, Semeraro ML, Malorni W and Iacobelli S: Galectin-3 overexpression protects from apoptosis by improving cell adhesion properties. Int J Cancer 85: 545-554, 2000.

209. Inohara H, Honjo Y, Yoshii T, Akahani S, Yoshida J, Hattori K, Okamoto S, Sawada T, Raz A and Kubo T: Expression of galectin-3 in fine-needle aspirates as a diagnostic marker differentiating benign from malignant thyroid neoplasms. Cancer 85: 2475-2484, 1999.

210.Pinedo HM, Verheul HM, D'Amato RJ and Folkman J: Involvement of platelets in tumour angiogenesis? Lancet 352: 1775-1777, 1998.

211.Pai R, Soreghan B, Szabo IL, Pavelka M, Baatar D and Tarnawski AS: Prostaglandin E2 transactivates EGF receptor: A novel mechanism for promoting colon cancer growth and gastrointestinal hypertrophy. Nat Med 8: 289-293, 2002.

212.Ikushima $H$ and Miyazono K: TGFbeta signalling: A complex web in cancer progression. Nat Rev Cancer 10: 415-424, 2010.

213. Sierko E and Wojtukiewicz MZ: Platelets and angiogenesis in malignancy. Semin Thromb Hemost 30: 95-108, 2004.

214. Medina VA and Rivera ES: Histamine receptors and cancer pharmacology. Br J Pharmacol 161: 755-767, 2010.

215. Moghaddam A, Zhang HT, Fan TP, Hu DE, Lees VC, Turley H, Fox SB, Gatter KC, Harris AL and Bicknell R: Thymidine phosphorylase is angiogenic and promotes tumor growth. Proc Natl Acad Sci USA 92: 998-1002, 1995.

216. Bronckaers A, Gago F, Balzarini J and Liekens S: The dual role of thymidine phosphorylase in cancer development and chemotherapy. Med Res Rev 29: 903-953, 2009.

217. Geiger TR and Peeper DS: Critical role for TrkB kinase function in anoikis suppression, tumorigenesis, and metastasis. Cancer Res 67: 6221-6229, 2007

218. Kim YJ, Borsig L, Varki NM and Varki A: P-selectin deficiency attenuates tumor growth and metastasis. Proc Natl Acad Sci USA 95: 9325-9330, 1998.
219. David M, Wannecq E, Descotes F, Jansen S, Deux B, Ribeiro J, Serre CM, Grès S, Bendriss-Vermare N, Bollen M, et al: Cancer cell expression of autotaxin controls bone metastasis formation in mouse through lysophosphatidic acid-dependent activation of osteoclasts. PLoS One 5: e9741, 2010.

220. Visentin B, Vekich JA, Sibbald BJ, Cavalli AL, Moreno KM, Matteo RG, Garland WA, Lu Y, Yu S, Hall HS, et al: Validation of an anti-sphingosine-1-phosphate antibody as a potential therapeutic in reducing growth, invasion, and angiogenesis in multiple tumor lineages. Cancer Cell 9: 225-238, 2006.

221. Ruf W and Mueller BM: Thrombin generation and the pathogenesis of cancer. Semin Thromb Hemost 32 (Suppl 1): 61-68, 2006.

222. Bajou K, Noël A, Gerard RD, Masson V, Brunner N, Holst-Hansen C, Skobe M, Fusenig NE, Carmeliet P, Collen D, et al: Absence of host plasminogen activator inhibitor 1 prevents cancer invasion and vascularization. Nat Med 4: 923-928, 1998.

223. Falcón BL, Hashizume H, Koumoutsakos P, Chou J, Bready JV, Coxon A, Oliner JD and McDonald DM: Contrasting actions of selective inhibitors of angiopoietin-1 and angiopoietin- 2 on the normalization of tumor blood vessels. Am J Pathol 175: 2159-2170, 2009.

224. Payne AS and Cornelius LA: The role of chemokines in melanoma tumor growth and metastasis. J Invest Dermatol 118: 915-922, 2002.

225. Wu Y, Li YY, Matsushima K, Baba T and Mukaida N: CCL3-CCR5 axis regulates intratumoral accumulation of leukocytes and fibroblasts and promotes angiogenesis in murine lung metastasis process. J Immunol 181: 6384-6393, 2008.

226.Läubli H, Spanaus KS and Borsig L: Selectin-mediated activation of endothelial cells induces expression of CCL5 and promotes metastasis through recruitment of monocytes. Blood 114: 4583-4591, 2009.

227. Yi F, Jaffe R and Prochownik EV: The CCL6 chemokine is differentially regulated by c-Myc and L-Myc, and promotes tumorigenesis and metastasis. Cancer Res 63: 2923-2932, 2003.

228. Keeley EC, Mehrad B and Strieter RM: CXC chemokines in cancer angiogenesis and metastases. Adv Cancer Res 106: 91-111, 2010.

229. Nakamura ES, Koizumi K, Kobayashi M, Saitoh Y, Arita Y, Nakayama T, Sakurai H, Yoshie O and Saiki I: RANKL-induced CCL22/macrophage-derived chemokine produced from osteoclasts potentially promotes the bone metastasis of lung cancer expressing its receptor CCR4. Clin Exp Metastasis 23: 9-18, 2006.

230.Romagnani P, Lasagni L, Annunziato F, Serio M and Romagnani S: CXC chemokines: The regulatory link between inflammation and angiogenesis. Trends Immunol 25: 201-209, 2004.

231. Strieter RM, Burdick MD, Gomperts BN, Belperio JA and Keane MP: CXC chemokines in angiogenesis. Cytokine Growth Factor Rev 16: 593-609, 2005

232. Feliciano P: CXCL1 and CXCL2 link metastasis and chemoresistance. Nat Genet 44: 840, 2012.

233. Keane MP, Belperio JA, Xue YY, Burdick MD and Strieter RM: Depletion of CXCR2 inhibits tumor growth and angiogenesis in a murine model of lung cancer. J Immunol 172: 2853-2860, 2004.

234. White ES, Flaherty KR, Carskadon S, Brant A, Iannettoni MD, Yee J, Orringer MB and Arenberg DA: Macrophage migration inhibitory factor and CXC chemokine expression in non-small cell lung cancer: Role in angiogenesis and prognosis. Clin Cancer Res 9: 853-860, 2003.

235. Strieter RM, Burdick MD, Mestas J, Gomperts B, Keane MP and Belperio JA: Cancer CXC chemokine networks and tumour angiogenesis. Eur J Cancer 42: 768-778, 2006.

236. Miyazaki H, Patel V, Wang H, Edmunds RK, Gutkind JS and Yeudall WA: Down-regulation of CXCL5 inhibits squamous carcinogenesis. Cancer Res 66: 4279-4284, 2006.

237.Gijsbers K, Gouwy M, Struyf S, Wuyts A, Proost P, Opdenakker G, Penninckx F, Ectors N, Geboes K and Van Damme J: GCP-2/CXCL6 synergizes with other endothelial cell-derived chemokines in neutrophil mobilization and is associated with angiogenesis in gastrointestinal tumors. Exp Cell Res 303: 331-342, 2005.

238. Verbeke H, Struyf S, Berghmans N, Van Coillie E, Opdenakker G, Uyttenhove C, Van Snick J and Van Damme J: Isotypic neutralizing antibodies against mouse GCP-2/CXCL6 inhibit melanoma growth and metastasis. Cancer Lett 302: 54-62, 2011. 
239. Tang Z, Yu M, Miller F, Berk RS, Tromp G and Kosir MA: Increased invasion through basement membrane by CXCL7-transfected breast cells. Am J Surg 196: 690-696, 2008.

240. Bachelder RE, Wendt MA and Mercurio AM: Vascular endothelial growth factor promotes breast carcinoma invasion in an autocrine manner by regulating the chemokine receptor CXCR4. Cancer Res 62: 7203-7206, 2002.

241. Belperio JA, Phillips RJ, Burdick MD, Lutz M, Keane M and Strieter R: The SDF-1/CXCL 12/CXCR4 biological axis in non-small cell lung cancer metastases. Chest 125 (Suppl 5): $156 \mathrm{~S}, 2004$
242.Pan J, Mestas J, Burdick MD, Phillips RJ, Thomas GV, Reckamp K, Belperio JA and Strieter RM: Stromal derived factor-1 (SDF-1/CXCL12) and CXCR4 in renal cell carcinoma metastasis. Mol Cancer 5: 56, 2006. 